\title{
Progress in Automotive Transmission Technology
}

\author{
Xiangyang $\mathrm{Xu}^{1,2} \cdot$ Peng Dong ${ }^{1,2} \cdot$ Yanfang $\mathrm{Liu}^{1,2} \cdot$ Hui Zhang ${ }^{1,2}$
}

Received: 21 June 2018 / Accepted: 31 July 2018 / Published online: 23 August 2018

(c) The Author(s) 2018

\begin{abstract}
Much progress has been made in the development of automotive transmissions over the past 20 years, e.g., an increased speed number, expanded ratio spread and improved efficiency and shift quality. Automotive transmissions are moving toward electrification in response to stringent legislation on emissions and the pressing demand for better fuel economy. This paper reviews progress in automotive transmission technology. Assisted by computer-aided programs, new transmission schemes are constantly being developed. We therefore first introduce the synthesis of the transmission scheme and parameter optimization. We then discuss the progress in the transmission technology of a conventional internal combustion engine vehicle in terms of new layouts; improved efficiency; noise, vibration and harshness technology; and the shifting strategy and control technology. As the major development trend, transmission electrification is subsequently discussed; this discussion includes the configuration design, energy management strategy, hybrid mode shifting control, single-speed and multi-speed electric vehicle transmission and distributed electric drive. Finally, a summary and outlook are presented for conventional automotive transmissions, hybrid transmissions and electric vehicle transmissions.
\end{abstract}

Keywords Automotive transmission - Hybrid transmission - Electric vehicle transmission - Distributed electric drive . Scheme synthesis $\cdot$ Electrification

\section{Abbreviations}

AMT Automated manual transmission

AT Automatic transmission

CD Charge depleting

CS Charge sustaining

CVT Continuously variable transmission

DCT Dual-clutch transmission

DHT Dedicated hybrid transmission

DOF Degree of freedom

ECVT Electric continuously variable transmission

EM Electric motor

EOP Electric oil pump

EV Electric vehicle

FWD Front-wheel driving

HEV Hybrid electric vehicle

Peng Dong

peng.dong@buaa.edu.cn

1 School of Transportation and Science Engineering, Beihang University, Beijing 100191, China

2 Beijing Key Laboratory for High-efficient Power Transmission and System Control of New Energy Resource Vehicle, Beihang University, Beijing 100191, China
ICE Internal combustion engine

ILC Iterative learning controller

MT Manual transmission

MOP Mechanical oil pump

NMPC Nonlinear model predictive controller

NVH Noise, vibration and harshness

OWC One-way clutch

PGP Parallel-axis gear pair

PGS Planetary gear set

PHEV Plug-in hybrid electric vehicle

PID Proportional-integral-derivative

R\&D Research and development

RGS Ravigneaux gear set

SE Shifting element

THS Toyota Hybrid System

\section{Introduction}

With pressing demands to reduce emissions and improve fuel economy, automotive transmissions have evolved over the past 20 years while rapidly progressing toward electrification. Conventional automotive transmissions for the 
internal combustion engine (ICE) are generally classified into manual transmission (MT), automated manual transmission (AMT), automatic transmission (AT), dual-clutch transmission (DCT) and continuously variable transmission (CVT). This review focuses on the progress of AT, DCT and CVT because they largely account for the development of transmission technology in the past 20 years and have gradually replaced MT and AMT in passenger cars.

Automotive transmissions are undergoing electrification to meet stringent legislations pushing for $\mathrm{CO}_{2}$ reduction. As electromechanical coupling systems, transmissions in hybrid electric vehicles (HEVs) and plug-in hybrid electric vehicles (PHEVs) are important in terms of achieving different driving modes, such as series, parallel and power-split modes. With the integration of the electric motor (EM) into conventional ATs, DCTs and CVTs are examples of transmission electrification and are normally realized by adding a hybrid module or replacing the launching element with a hybrid module. Such add-on solutions have excellent inheritance because most parts can be shared between conventional transmissions and hybrid transmissions, which facilitates modular design and manufacture. In contrast to add-on solutions, dedicated hybrid transmissions (DHTs) are completely newly developed for HEVs and PHEVs. The complexity of a mechanical system is generally lower than that of conventional multispeed transmissions.

As for electric vehicles (EVs), single-speed gearboxes are most commonly used today. It is not necessary for an EV to have a complex multi-speed transmission owing to the torque and efficiency characteristics of the EM. However, a two- or three-speed transmission can benefit the miniaturization of the EM in terms of reducing the EM peak torque. Furthermore, energy consumption can be reduced by optimizing the operating points of the EM through gear shifting. Many companies have therefore developed twoor three-speed transmissions for EVs. To improve the efficiency and reduce weight, EV transmission tends to be fully integrated with the EM and power electronics. The distributed electric drive is one direction of the research and development (R\&D) of EVs, and it has attracted much attention because of its simple vehicle architecture and high drive efficiency. Some in-wheel motors are close to industrialization.

Along with the development of HEVs, PHEVs and EVs, automotive transmission technology is currently in a transition phase moving toward electrification. It is thus necessary to review and provide an outlook for the development of automotive transmission. The remainder of the paper is organized as follows. Section 2 introduces the synthesis of a transmission scheme and parameter optimization. Section 3 discusses the progress in the transmission technology of a conventional ICE vehicle. Section 4 presents the state of the art of electrified transmission technology for HEVs, PHEVs and EVs.
Finally, a summary and future research directions are presented.

\section{Synthesis of a Transmission Scheme and Parameter Optimization}

Regarding the development of automotive transmissions, the first step is to find a competitive transmission scheme with high power density, high efficiency and low $R \& D$ costs. This section introduces the theory and methodology of the synthesis of the transmission scheme. The parameter optimization of transmission schemes is also reviewed in this section.

\subsection{Synthesis of the Transmission Scheme}

An AT is a system having multiple degrees of freedom (DOFs) mechanically connected by several planetary gear sets (PGSs), parallel-axis gear pairs (PGPs) and shifting elements (SEs). It achieves different gear ratios by engaging different SEs to reduce the number of DOFs of the system. Depending on the numbers of PGSs, SEs and DOFs, the maximum number $N$ of candidate transmission schemes can be calculated as [1]

$N=C_{C_{n+p}^{3}}^{p} \times C_{C_{n+p}^{2}}^{L} \times\left(A_{3}^{3}\right)$,

where $L, n$ and $p$ are, respectively, the numbers of SEs, DOFs and PGSs.

Taking the synthesis problem of a transmission scheme with three PGSs, three SEs and four DOFs as an example, the total number of candidate transmission schemes is about 1.9 billion, among which it is difficult to find the best. Several synthesis methods have been proposed in the literature to solve this complex problem.

\subsubsection{Benchmark Method}

The benchmark synthesis method starts from a basic scheme, which can be selected from existing transmission schemes having good performance [2]. By adding or removing partial PGSs and SEs or tuning the stationary ratio of PGSs and PGPs [3], a new transmission scheme is extended from the basic scheme. Dong synthesized a 13-speed AT scheme based on an eight-speed AT scheme by adding one SE [4], as shown in Fig. 1. A 9-, 11- or 13-speed clutching sequence can be realized by tuning the stationary ratios of PGPs.

The method requires little calculation effort to facilitate manual operation. However, it relies heavily on the experience of the designer and the features of the selected basic scheme. Therefore, the final solution is usually not a global optimal solution. 

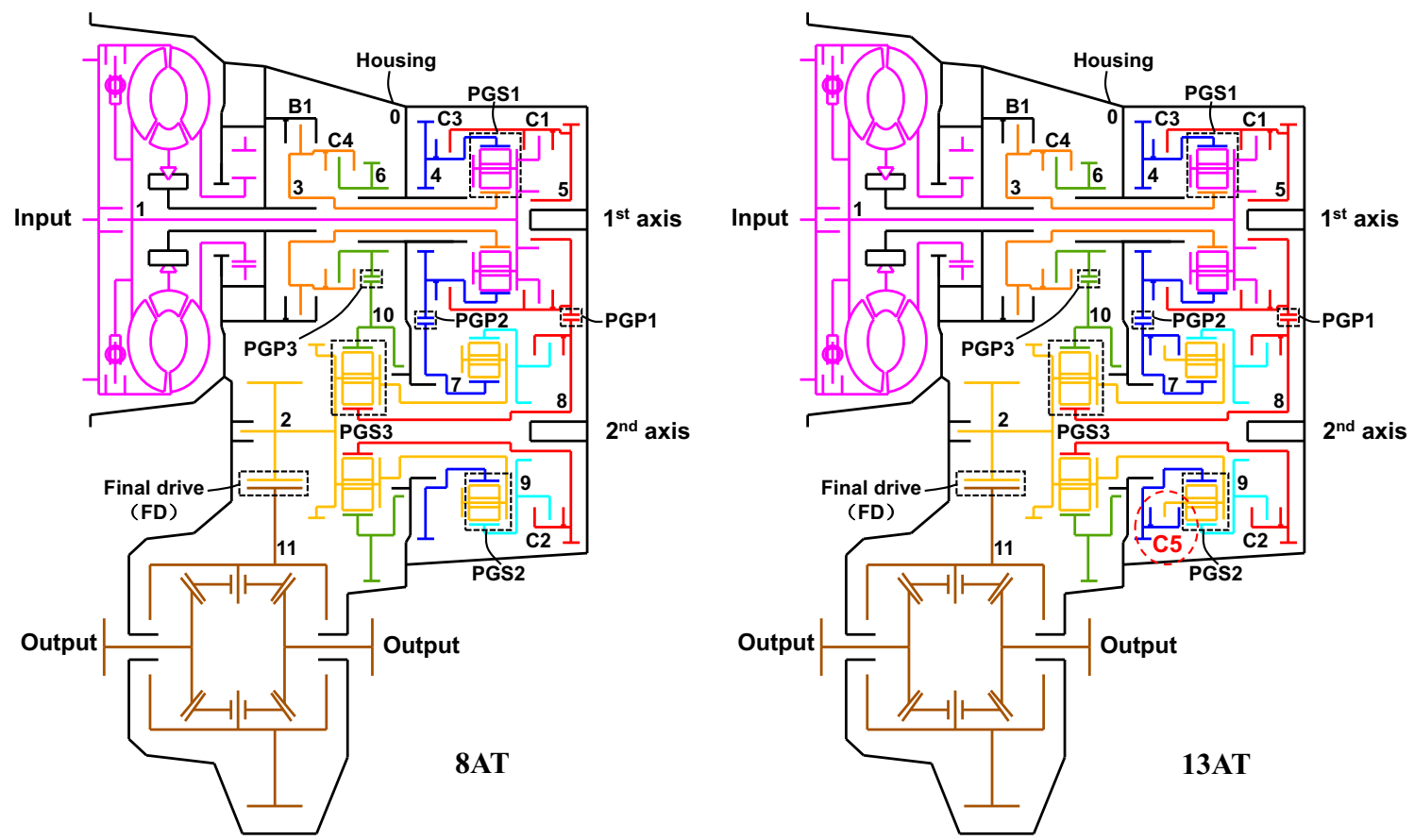

Fig. 1 Transmission schemes of eight-speed and 13-speed ATs. (Reproduced with permission from [4])

\subsubsection{Line Chart Analysis Method}

New transmission schemes can be inspired through analysis of the relative rotational speed relationship of each basic component of a scheme [5], as shown in Fig. 2. By determining the sequence of the gear ratio, all possible gears can be found. Auxiliary components are added to the connection of each gear, and the numbers of PGSs and SEs are obtained. According to the rational speed of each basic component, the performance of the scheme is obtained [6]. Constraints are imposed on the connection conditions of the gears, and the synthesis process is greatly simplified [7].

The method has low computational accuracy and requires a high level of professional skill [8]. With an increasing number of DOFs, the transmission scheme becomes increasingly complex such that synthesis based on this method becomes tedious. It is also difficult to synthesize all feasible transmission schemes.

\subsubsection{Component Analysis Method}

Wan [9] proposed a synthesis method based on component analysis in 1965 as shown in Fig. 3. By analyzing important factors, such as the combinations of basic components of PGSs and their structural and parametric characteristics, all feasible schemes are deduced. A variety of early transmissions were successfully found using this method.

However, with increasing numbers of PGSs, SEs and speeds, the number of candidate transmission schemes

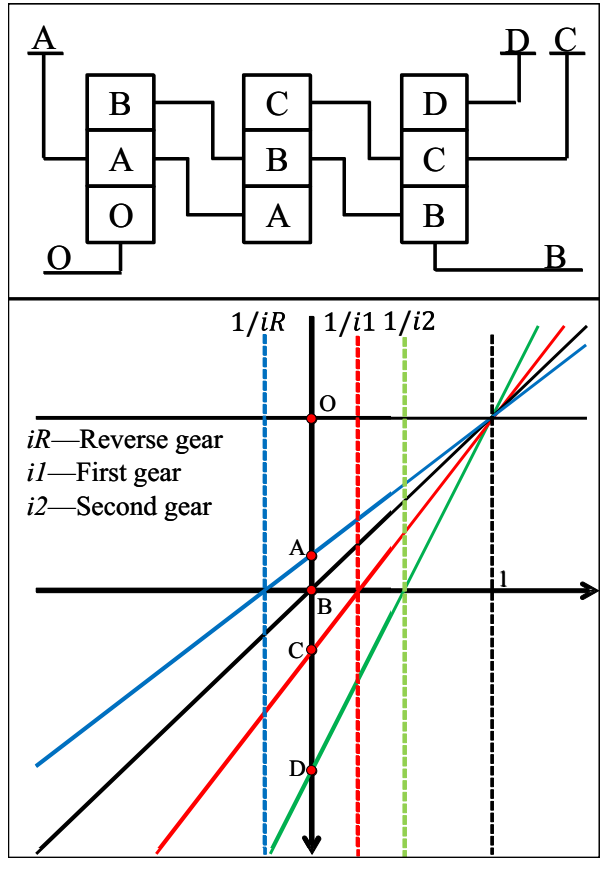

Fig. 2 Line chart representation of a two-DOF transmission scheme. (Reproduced with permission from [6])

increases dramatically [10], as does the calculation effort. It is therefore mostly agreed that this method is effective for the synthesis of a transmission scheme with fewer than three DOFs [11]. 


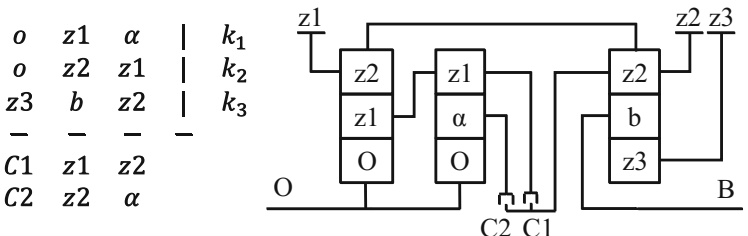

Fig. 3 Component analysis method

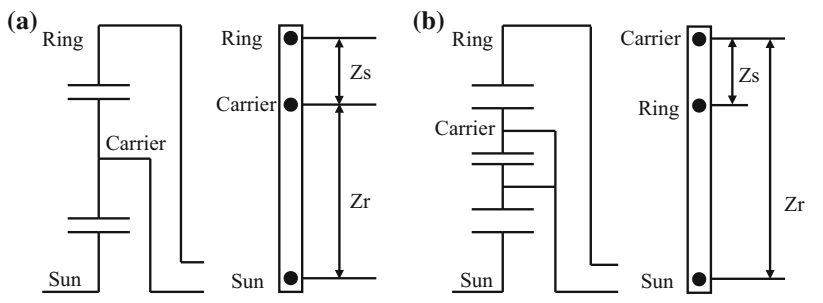

Fig. 4 Lever representation of a PGS

\subsubsection{Lever Analysis Method}

A PGS can be represented by a lever, where the kinematics between the sun gear, ring gear and planet carrier follows the lever rule [12-14], as shown in Fig. 4. Therefore, the lever method is largely intuitive. However, the overall scheme needs to be simplified to a two-DOF system, and this becomes more exhaustive work for the synthesis of a scheme having more than three DOFs.

\subsubsection{Graph Theory Method}

By defining all components as points and their connections as edges on a planar graph, graph theory performs well in representing AT schemes as shown in Fig. 5. In addition, the planarity checking algorithm of graph theory can be used to judge the structural feasibility of transmission schemes for further evaluation and parametric optimization $[15,16]$. Therefore, the synthesis of a transmission scheme based on graph theory is much easier for computer implementation $[17,18]$. Much effort has been put into this method and improved synthesis models based on graph theory have been proposed [19-21]. Li [22] built a graph theory model for scheme synthesis where the PGS was taken as a basic unit and computer-aided design was implemented employing component analysis.

\subsubsection{Coding Synthesis Method}

Gumpoltsberger proposed a shaft coding synthesis method for an AT scheme with PGSs. The basic shaft components of each PGS are coded. With the permutation and combination algorithm, a complete coding sequence that can construct all possible transmission schemes is integrated. This method is outstanding when synthesizing transmission schemes have
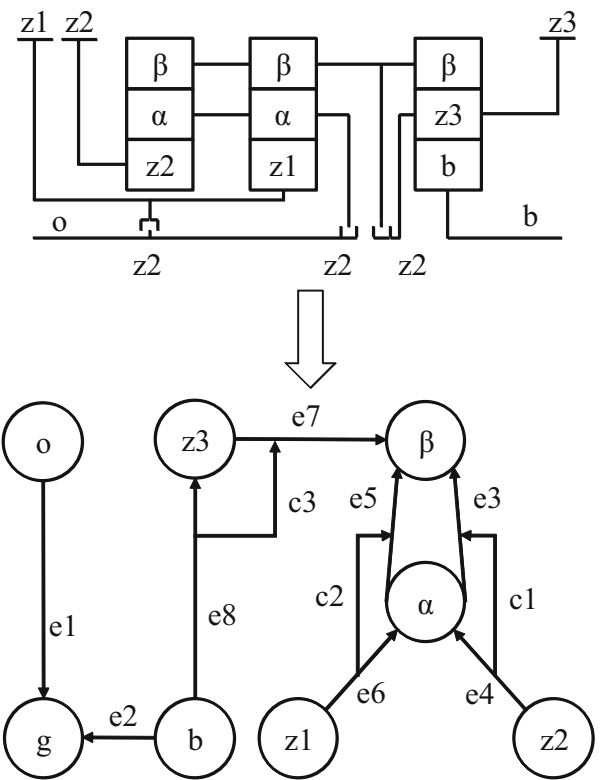

Fig. 5 Structural representation based on graph theory. (Reproduced with permission from [22])

more DOFs. However, the initial scheme database is usually large such that the overall computational efficiency is low because more memory and more calculation effort are required to remove unreasonable schemes [23]. Ma built a synthesis model for a four-DOF AT scheme by combining the shaft coding rule, component analysis and graph theory. She combined the depth-first searching algorithm and the D.M.P. algorithm to improve the computational efficiency $[24,25]$.

In general, the benchmark method, line chart analysis and lever analysis can be used to quickly synthesize and analyze new schemes. However, these methods place extremely high demands on the designer. Additionally, they are only suitable for synthesizing schemes with fewer than three DOFs. The graph theory method converts the scheme into a graph model and eliminates solutions having mechanical interference. The component analysis method and the code synthesis method can obtain all possible schemes by enumeration. However, with increasing numbers of DOFs and PGSs, the scheme becomes more complex. More detailed constraints need to be established to reduce the computational time.

The position of the EM must be considered when synthesizing DHT schemes. Many works have studied the configuration design of a DHT system on the basis of previous achievements of AT synthesis. Studies have established lever models for one or two PGSs. The DHT schemes can be obtained by determining the connecting position of the engine and EM [26, 27]. However, this leverage analysis for the synthesis of DHTs is also only suitable for two or three DOFs because of its complex lever conversion rules. 
Graph theory is also applied for the synthesis of DHTs [28-30]. A graph model of PGSs is first built. A certain number of points are randomly selected as the fixed connections to the energy resource. Clutch connections are then introduced into the graph model. All design schemes are obtained by traversing all points. Peng proposed a model-based design method to realize the above design process efficiently [28, 31]. By analyzing the characteristics of each operating mode of DHT systems [32], different constraints are deduced and the configuration schemes that meet the design requirements are finally obtained [33-37]. Meanwhile, the corresponding computational algorithms for the structural design of DHT systems have been discussed by taking the wheelset as the basic topology unit in graph theory [38, 39]. Although a design process and its computer-aided synthesis based on graph theory have been employed, it remains necessary to focus on how to find the best solution with multiple DOFs and high efficiency.

FEV proposed an integrated approach for synthesizing multi-axial DCT schemes. By introducing the dual-clutch shaft into the power transmission path, a plurality of DCT schemes with $n+x$ gears are synthesized, each having the same structural dimensions as the original DCT schemes with $n$ gears [40]. Leesch proposed a synthesis method for DCT schemes that involves traversing the power flow path [41].

In summary, many studies on the synthesis of transmission schemes have been conducted. However, with the increasing numbers of components and DOFs, the computational efficiency of synthesis is declining because more time is required for the detection of mechanical interference and isomorphic schemes. Therefore, how to improve the versatility and efficiency of the synthesis algorithm will be an ongoing research hotspot.

\subsection{Parameter Optimization}

The performance of a transmission scheme in terms of, for example, the gear ratios, mechanical efficiency and structural compactness will depend on design parameters. It is therefore essential to find the optimal parameters with which to design a transmission scheme with good performance [42]. However, this is difficult because there are a great many parameters and many optimization goals.

Most work nowadays focuses on the parametric optimization of the stationary ratios of PGSs. Ideal transmission ratios for all gears are usually given in advance by experienced engineers as the initial optimization target. The transmission ratio of each gear is determined by the stationary ratios of PGSs. Some numerical algorithms, such as dynamic programming, ant colony, particle swarm and genetic algorithms, have been shown to be effective for solving such problems [4, 43].

There remain strict requirements in addition to the transmission ratios [44] in the parametric design of a transmission scheme. However, the computational effort increases dramatically once these are taken into account. For conventional ATs, how to build a parametric optimization model considering as many factors as possible will be another ongoing research hotspot. Chen proposed an improved minimum and maximum principle to optimize the detailed gear parameters (including the gear modulus, gear teeth number and gear width) of a two-speed transmission scheme and built an optimization model for the optimal dynamic and economic performance [45, 46]. For DHTs in HEVs and PHEVs, the main focus is energy management and mode shifting control [47]. However, the coordination of multiple power sources is also an important factor, and few published works have focused on structural parametric optimization design.

\section{Progress in the Transmission Technology of a Conventional ICE Vehicle}

This section gives a general review of the latest developments of conventional automotive transmission for the ICE. The transmission layout synthesis, efficiency improvement, noise, vibration and harshness (NVH) technology, shifting strategy and control technology are discussed separately.

\subsection{Transmission Layout Synthesis}

Novel AT and DCT schemes have continuously emerged in recent years with an increasing number of speeds. A growing number of automakers are introducing these novel multi-speed transmissions to their vehicles, as a part of a continuing effort to improve the drivability and fuel economy of their vehicles. On the one hand, the highest gear ratio has been decreased to improve fuel economy when a vehicle is cruising. On the other hand, the lowest gear ratio has been increased to improve drivability when a vehicle is launching or creeping. The increasing speed number allows for smaller gear steps that provide comfort and smooth shifts. CVT schemes have not changed greatly. The main type is still the chain or belt drive. Jatco integrated an auxiliary gearbox with one Ravigneaux gear set (RGS) and three SEs to achieve a wider ratio spread [48]. Other CVT concepts, such as the toroidal variator, are still far from industrialization.

\subsubsection{AT Schemes}

Figure 6 shows AT schemes of different companies for longitudinal application. In 2001, ZF launched its six-speed AT based on the Lepelletier concept with one single PGS, one RGS and five SEs [49]. In 2007, ZF introduced its eight-speed AT with four PGSs and five SEs instead of the Lepelletierbased structure [50]. The system has four DOFs, which means three SEs need to be engaged for each speed. This 


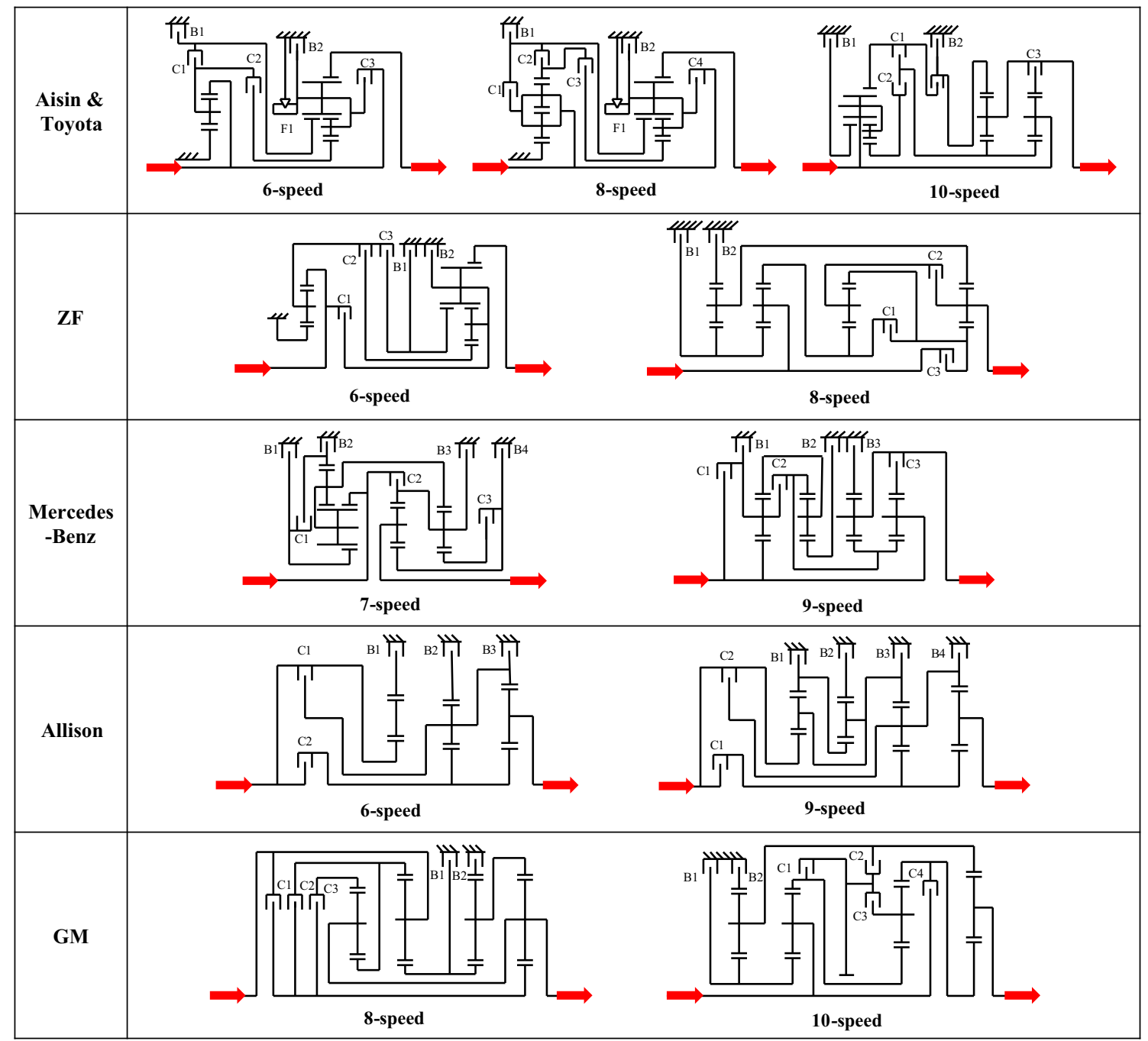

Fig. 6 AT schemes of different companies for longitudinal application

transmission is a market benchmark in that it offers considerable progress in terms of fuel savings, the power-to-weight ratio and functionality.

Aisin developed a six-speed AT for rear-wheel-driving vehicles based on the Lepelletier concept [51]. A new eightspeed AT was then released in 2007 by Aisin and Toyota jointly, again on the basis of the Lepelletier concept [52]. However, the stationary ratio of the single PGS changes from negative to positive and there is one more clutch than for the six-speed AT. In 2017, Aisin and Toyota introduced their new 10-speed AT. The gear train is made up of one RGS, two single PGSs, four clutches and two brakes [53]. In comparison with their eight-speed AT, ten speeds are achieved using the same number of SEs but one more single PGS. This new gear train also has four DOFs. In addition, the one-way clutch (OWC) for the shift between first and second gears is eliminated.
Mercedes-Benz, in 2003, released its seven-speed longitudinal AT, which consists of one RGS, two single PGSs and seven SEs [54]. Although it was the first gear train having four DOFs on the market, there are still four SEs disengaged for each speed, which produces large drag torque. In 2015, Mercedes introduced its nine-speed longitudinal AT. The gear train is again a four-DOF system that has four single PGSs, but the number of SEs is reduced to six [55]. A specific software tool was developed to find this transmission scheme within specific constraints, such as those of the size, ratio, spread and optimal gear efficiency.

GM and Ford jointly developed eight-speed and 10-speed longitudinal ATs. The eight-speed AT has a transmission scheme similar to that of the ZF eight-speed AT including four single PGSs, three clutches and two brakes [56]. The 10-speed AT has one more clutch and was the first AT in mass production having five DOFs [57]. Allison is now develop- 


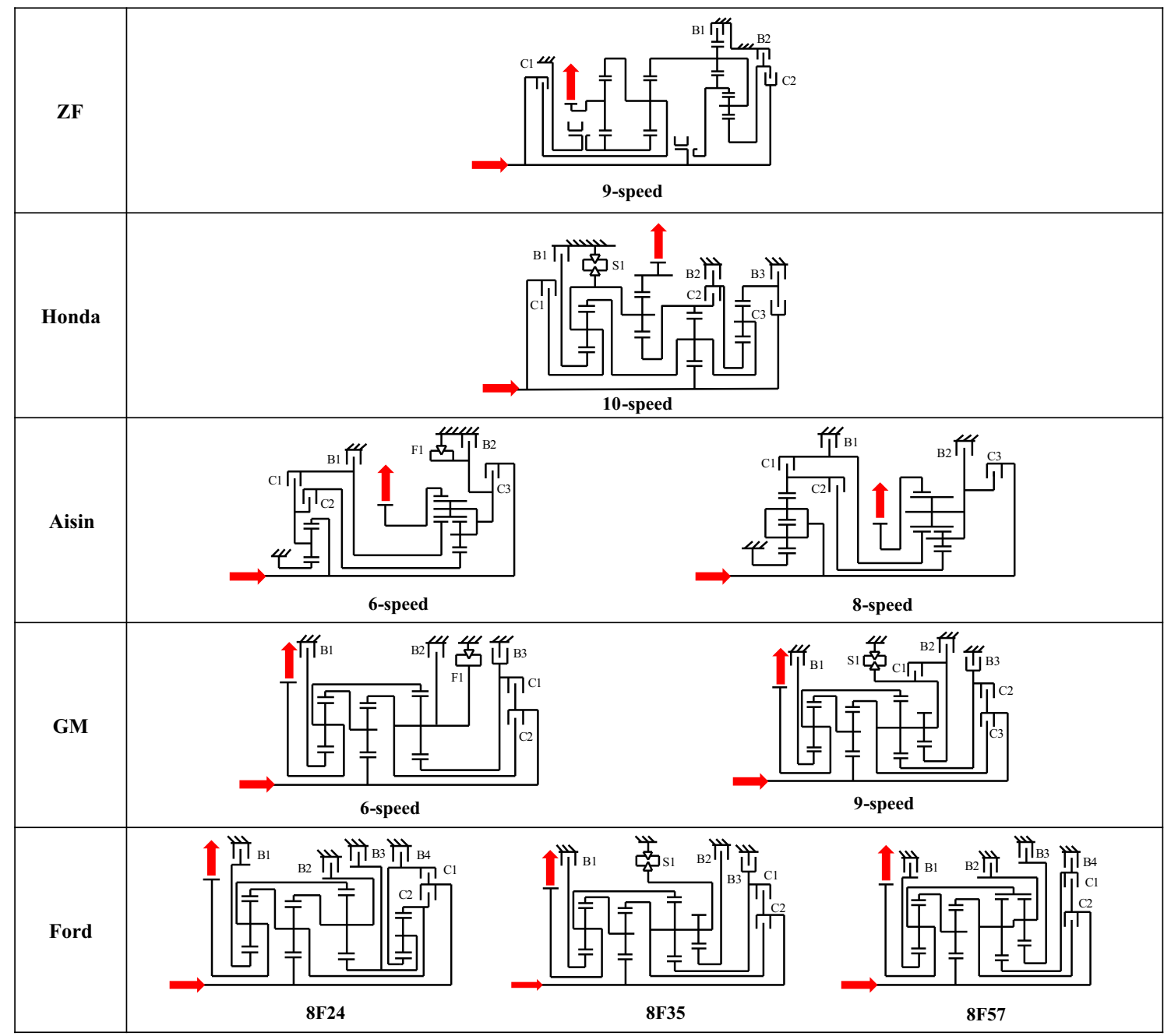

Fig. 7 AT schemes of different companies for front-transverse application

ing a nine-speed AT for the medium-duty commercial truck market [58]. An additional PGS and brake have been added on the basis of Allison's proven reliable six-speed AT. The new gear train features four PGSs and six SEs. Prototypes are being tested internally.

Front-wheel-driving (FWD) vehicles account for $75 \%$ of the market of passenger cars. Regarding ATs for fronttransverse application, cost and size pressure is even higher because FWD vehicles are particularly prevalent in the costsensitive market of compact and mid-size cars. Figure 7 shows the AT schemes of different companies for fronttransverse application. ZF, in 2013, launched its nine-speed AT with four single PGSs and six SEs [59]. In terms of size, the length of a front-transverse AT is important. In consideration of the installation space, ZF arranged the PGSs and SEs in a nested manner. Additionally, two dog clutches were first applied as SEs in ATs because of their small diameter and length.
The front-transverse ATs of Aisin are also Lepelletierbased structures [60, 61]. Aisin introduced six-speed and eight-speed ATs to the market in 2004 and 2013, respectively. GM developed its six-speed AT with three single PGSs, two clutches, four brakes and one OWC [62]. On the basis of this scheme, GM developed a nine-speed AT that they launched to market in 2017 [63]. The nine-speed AT uses a compound PGS to replace one single PGS. By means of one selectable OWC, only one SE is added in the new scheme. Ford developed three eight-speed ATs having different engine torques [64]. The 8F35 and 8F57 are based on the six-speed and nine-speed ATs jointly developed by GM and Ford.

Honda is well known for its four-speed and five-speed countershaft-type ATs. However, it is difficult to increase the speed number using only PGPs. In 2017, Honda introduced its novel 10-speed AT with four single PGSs, three brakes, three clutches and one selectable OWC [65]. Shengrui developed an eight-speed AT by combining three single 


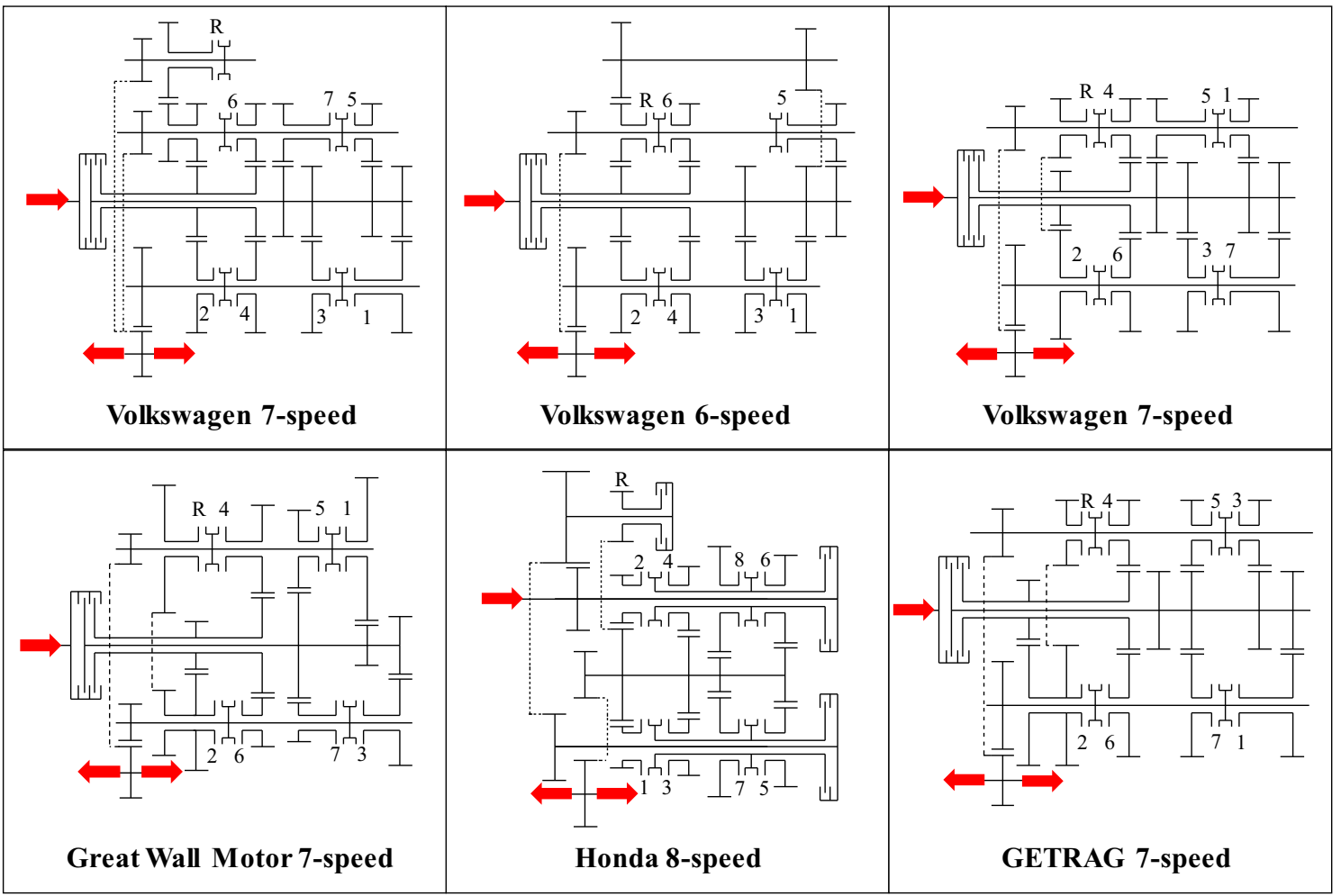

Fig. 8 DCT schemes of different companies

PGSs, three PGPs and five SEs on two parallel axes [66]. A nine, eleven or thirteen-speed clutching sequence can be realized by adding one clutch and tuning the stationary ratio of the three PGPs [4].

\subsubsection{DCT Schemes}

DCTs combine the advantage of MTs (i.e., high efficiency) with that of ATs (i.e., power shifts). Owing to the lack of a torque converter, DCTs require a higher first gear ratio to launch the vehicle.

Figure 8 presents several DCT schemes that are in mass production. The first DCT for passenger cars, DQ250 from Volkswagen (VW), went into serial production in 2003 [67]. A wet multi-plate dual-clutch module from BorgWarner is applied to divide the gears into odd gears and even gears. An advantage of DCT over AT is that only one disengaged clutch causes drag losses. In 2007, VW introduced its sevenspeed DCT with a dry dual-clutch module from LuK [68]. Compared with DQ250, DQ200 has higher efficiency but lower torque capacity. DQ500 came onto the market in 2009 [69] and is a seven-speed DCT with a wet multi-plate dualclutch module. VW uses this DCT in larger and higher-output vehicles.

The success of the VW DCT sets a benchmark in terms of the shift speed, sports performance and efficiency. Other vehicle or transmission manufacturers, such as GETRAG, Great Wall and Geely, have started developing their own DCTs. Honda released its eight-speed DCT in 2014 with an ultra-flat torque converter, the adoption of which helps vehicles launch powerfully and smoothly. Additionally, instead of the integrated dual-clutch module in conventional DCT, the dual clutch is separately arranged on parallel shafts to reduce inertia [70].

DCTs are mainly applied for FWD vehicles. To achieve more speeds, DCTs must have more PGPs, synchronizers and forks. However, this is difficult to realize within the limited space of the engine compartment. Therefore, the speed number of DCTs is currently less than that of ATs. It has been reported that VW was once developing a 10-speed DCT adopting the winding gear concept but this effort has since been terminated.

\subsection{Efficiency Improvement}

Transmissions have tended to have more speeds in recent years because of legislative pressure relating to $\mathrm{CO}_{2}$ reductions and fuel economy. However, driving simulations indicate that increasing the speed number beyond 10 will not improve the fuel economy appreciably [71]. Different optimization approaches have therefore been investigated for 


\begin{tabular}{|c|c|c|c|}
\hline $\begin{array}{c}\text { Type of return } \\
\text { springs }\end{array}$ & $\begin{array}{c}\text { Multi-coil } \\
\text { spring pack }\end{array}$ & $\begin{array}{c}\text { Slotted disc } \\
\text { spring }\end{array}$ & $\begin{array}{c}\text { Separating } \\
\text { spring }\end{array}$ \\
\hline $\begin{array}{c}\text { Drag torque } \\
\text { reduction }\end{array}$ & No & No & Yes \\
\hline Graphic & & \\
\hline Installation & &
\end{tabular}

Fig. 9 Different types of return spring. (Reproduced with permission from [72])

mechanical and hydraulic systems to improve transmission efficiency.

\subsubsection{Mechanical System}

The transmission scheme is important in terms of improving the efficiency of a mechanical system. Newly developed ATs usually have four or even five DOFs instead of three DOFs because it means that fewer SEs are disengaged for each speed, resulting in small drag losses. Optimizations regarding friction loss and drag torque loss are continuously in progress on the component level. Low-friction bearings, seals and damper systems have gradually become popular in ATs, DCTs and CVTs, contributing greatly to improvements in efficiency.

Mubea developed new separating springs using waved disks positioned among clutch plates [72]. As shown in Fig. 9, compared with the coil spring and disk spring, the drag torque losses of disengaged SEs can be greatly reduced through the active separation of clutch plates. A potential drag torque reduction of up to $5 \mathrm{Nm}$ can be achieved using separating springs. In addition, the separating spring provides installation space savings. There is the potential to further reduce drag torque losses on the clutch lining surface by, for example, optimizing the groove pattern, groove shape and friction material. The design optimization of the clutch lining surface has been studied in simulation and experiment [73, 74].

ZF applied two dog clutches in their nine-speed AT and investigated the feasibility of applying dog clutches in their longitudinal eight-speed AT. Simulation results of the New European Driving Cycle show that a potential fuel saving of $1.1 \%$ can be achieved by replacing the two brakes of the eight-speed AT with dog clutches [50]. However, dog clutches are not widely applied in ATs because of the concern about shift quality. To reduce drag torque losses, the

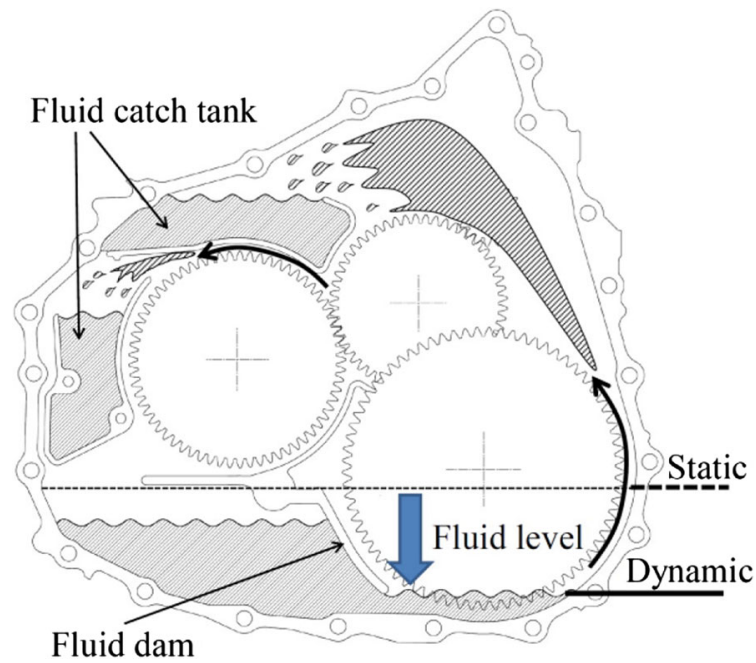

Fig. 10 Fluid dam and catch tank. (Reproduced with permission from [75])

brake for reverse and the low forward gear are replaced by integrating a selectable OWC in Ford eight-speed, GM ninespeed and Honda 10-speed ATs. The use of a dry dual-clutch module can improve the efficiency of the DCT because there is no oil sheared between plates. Nevertheless, the torque capacity of a dry clutch is limited.

Gear churching accounts for a large portion of torque losses in transmissions. To reduce gear churching, current transmissions adopt a fluid dam between the differential and housing. Fluid catch tanks are designed on the housing to catch the oil pumped up by the final gear. The oil flow around the final gear can thus be optimized and the fluid level can be reduced as shown in Fig. 10. As a result, gear churching losses can be minimized.

The efficiency of CVTs is generally lower than that of ATs and DCTs. However, it has improved greatly during the last decade. Jatco [22] developed a new variator system for its CVT7 W/R, which increased the friction coefficient between the belt and pulleys by means of optimized flank geometry and higher sheave stiffness. The pulley thrust force for clamping the belt can thus be reduced, decreasing the line pressure and oil pump driving torque. In addition, the relative slipping between belt elements and bands as well as the clearance between belt elements are reduced by means of a smaller rocking edge height and endplay, reducing the belt internal friction and thus mechanical losses.

\subsubsection{Hydraulic System}

The hydraulic system occupies a large portion of torque losses in transmissions. To reduce the drive torque of an oil pump, many transmissions adopt a newly designed pump system. Aisin optimized the gear design of the oil pump in its eight-speed AT. As a result, the pump diameter was reduced 


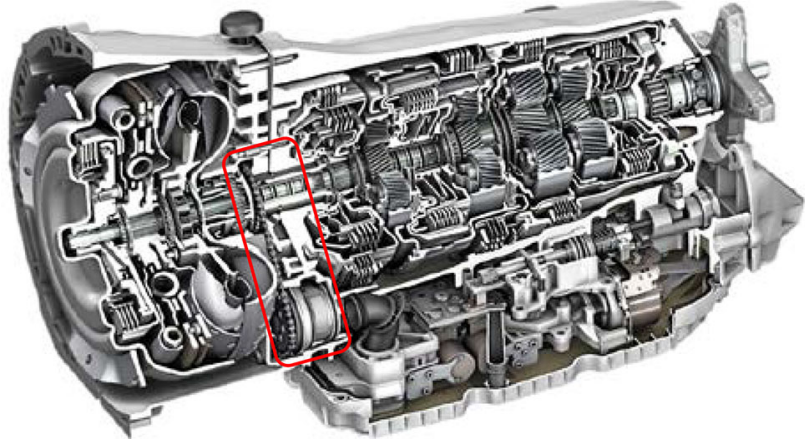

Fig. 11 Position of the vane-type pump in the Mercedes-Benz ninespeed AT. (Reproduced with permission from [55])

by $9.4 \%$ and the drive torque was reduced by $33 \%$ relative to the oil pump in Aisin's six-speed AT [61]. Jatco downsized the oil pump and optimized the valve geometry and oil channel in its CVT7 W/R. The internal friction of the oil pump was ultimately reduced by $30 \%$ [76].

ZF first adopted a vane-type pump instead of a gear-type pump in its eight-speed longitudinal AT. The vane-type pump has lower leakage and higher efficiency than the conventional gear-type pump. A consumption advantage of about $0.8 \%$ was achieved using the vane-type pump in the ZF eight-speed AT [50]. The vane-type pump is generally positioned off-axis close to the oil tank via a chain drive, as shown in Fig. 11, resulting in short paths and flow-favorable ducting and cross sections. The suction height can be reduced, and cavitation can be avoided. The energy loss is thus reduced.

The vane-type pump has become increasingly popular in transmissions because of its high volumetric and mechanical efficiency. However, excessive oil flow will result in large losses at high engine speed because the mechanical oil pump (MOP) depends on the input speed. To solve this issue, novel transmissions have been developed with a smaller MOP and integrated auxiliary electric oil pump (EOP). The smaller MOP reduces losses at high engine speed while the EOP can support the MOP for oil flow at low engine speed. Such a twopump system has been widely applied to improve efficiency. Dong [77-79] investigated the two-pump system through driving simulation. Results showed that there was a best combination of the sizes of the MOP and EOP with respect to optimal energy conservation. The energy consumption of the two-pump system could be reduced by $40 \%$ compared with the original one-pump MOP. Additionally, a stop-start capability can be achieved using the two-pump system.

A directly operating solenoid valve has gradually replaced the conventional pilot solenoid valve in ATs. Compared with the pilot control system, the directly operating solenoid valve is advantageous in terms of leakage and accuracy. Higher efficiency can therefore be achieved. In addition, a directly operating solenoid valve greatly reduces the hard- ware requirements of the valve body. The total number of valves in the Aisin eight-speed longitudinal AT has been reduced by $20 \%$ compared with conventional ATs [52]. Transmission fluid in ATs, DCTs and CVTs tends to have lower viscosity in the normal temperature region with the aim of reducing agitation resistance and thus improving efficiency. However, more attention needs to be paid to leakage. In ATs and CVTs, the torque converter is important for comfortable vehicle launching. However, the transmission efficiency is poor when the torque converter is in a hydrodynamic condition with the lock-up clutch disengaged. Therefore, the lock-up region of the torque converter expands toward the area of low speed and torque constantly with the help of an improved damper system and multi-disk lock-up clutch.

\subsection{NVH Technology}

The noise and vibration arising from automotive transmission are transmitted to passengers through airborne and structureborne paths and lead to discomfort [80]. Hence, the NVH problem in automotive transmission affects the vehicle driving comfort.

Whining, rattling, clunking, shifting and bearing noises are the five main types of noise in automotive transmission. The whining noise is related to two main excitations of loaded gear pairs: transmission error and time-varying mesh stiffness [81-83]. The transmission error is defined as the deviation of the actual meshing position from the theoretical position, which is strongly affected by gear manufacturing errors, assembly errors and tooth deformations. The timevarying mesh stiffness arises from the varying number of engaging teeth. The rattling noise is induced by the backlash of loose parts, such as the forward and backward vibrations of unloaded gear pairs and synchronizers [84-86]. This type of noise can be typically found in DCTs because of the coupling of PGPs and synchronizers, especially at idling and low speeds. The clunking noise arises at the moment that the flanks of active components knock against each other [87]. A shifting noise occurs when the synchronizer or clutch is not functioning correctly [88]. This type of noise depends on tooth errors and the shift strategy and is an important factor in evaluating the NVH quality of automotive transmission. Bearing noise is always masked by other types of noise unless damage occurs, and it increases in magnitude rapidly as the level of damage increases. Damage can therefore be diagnosed according to noise characteristics in early stages [89].

The noise in automotive transmissions is transmitted to passengers as airborne noise and structure-borne noise [80, 83], as shown in Fig. 12. The airborne noise is directly transmitted to passengers from the excitation source or radiated through the gearbox. The structure-borne noise is generated 


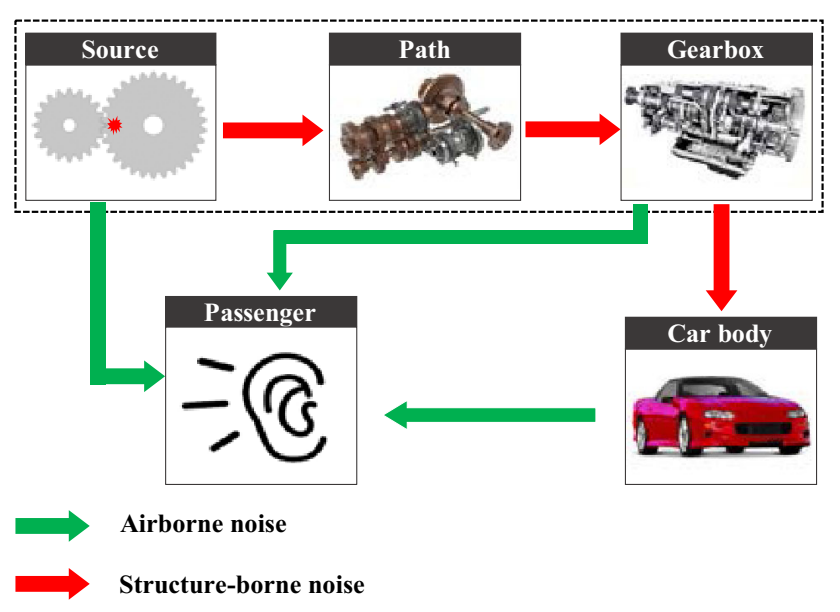

Fig. 12 Passage of airborne and structure-borne noise

by an excitation source and transmitted to passengers through the shafts, bearings, mountings and car body.

Active and passive measures are often adopted to improve the NVH quality of automotive transmissions. Active measures are mainly concentrated on addressing noise sources. A high-contact ratio gear, helical gear, modified tooth profile and high-quality tooth surface can reduce the gear whining noise $[83,90]$. Minimizing the backlash and the inertia of loose parts, optimizing the synchronizer design and reducing torsional vibration from the ICE can help reduce the rattling noise [91]. Furthermore, a torsional damper, dual mass flywheel or pendulum absorber is often placed between the engine and transmission to reduce vibration and fluctuation from the ICE and thus effectively suppress the rattling noise and vibration of the gearbox. Passive measures relate to transmission routes of structure-borne noise from the noise source to the car body. Examples of passive measures include increasing the stiffness of gear bodies, shafts, bearings and housings and separating the natural frequencies of these components and tuning the transmission mounting [92].

\subsection{Shifting Strategy and Control Technology}

The biggest complaint of customers relating to ATs and DCTs relates to the shift quality. The control of the shifting process is therefore important. Transmission manufacturers improve shift quality through both hardware and software development. In terms of hardware development, a directly operating solenoid valve is used in novel ATs and DCTs to improve the control accuracy. A torque converter with a flat and smalldiameter torus and a clutch hub with high-strength aluminum are applied in the Aisin 10-speed longitudinal AT [53], which reduces rotational inertia to realize a short shifting time. The piston chamber volume of each SE is also reduced to prevent a long shift response due to piston or cylinder movement in clutch engagement.

In terms of software development, numerous studies have investigated shifting strategies and control technologies. The shifts in ATs and DCTs are clutch-to-clutch shifts without power interruption. During torque transference from the off-going clutch to the on-coming clutch and speed synchronization from the current gear to the target gear, drivers expect a fast and smooth transition without drivetrain jerking, resulting in a demand for a high-quality shift.

The two primary challenges for wet-clutch control are (i) the intrinsically complex and nonlinear behavior [93] and (ii) the diversification of the dynamics over time due to changes in load, oil temperature and wear [94]. Studies [95-97] have focused on developing dynamic models of automotive transmissions in the shifting process. Relevant studies have also concentrated on different control approaches using a learning algorithm in the clutch control system. For instance, the two-level nonlinear model predictive controller (NMPC) and iterative learning controller (ILC) for wet-clutch control have been compared [98]. Meanwhile, the potential of several model-based (i.e., NMPC, ILC and iterative optimization) and model-free (i.e., genetic-based machine learning and reinforcement learning) learning strategies have been analyzed for the control of wet clutches [99].

There are generally three phases in clutch-to-clutch shifts: the fill phase, torque phase and inertia phase [100-102]. The clutch fill control is affected by many factors, such as characteristics of the clutch actuation system, oil temperature and engine speed [103]. Inaccurate clutch fill control can result in either an under-fill or an over-fill [104, 105]. It is necessary to implement methodologies in clutch fill control. Clutch fill control was improved to some extent using a new customized numerical dynamic programming method with pressure sensors [106]. An adaptive sliding mode observer has been implemented [107] to improve the online estimation of the turbine torque and hence improve the accuracy of the clutch pressure estimation in the fill phase.

In terms of control strategies for the torque phase, models and algorithms have been proposed according to the dynamic characteristics of the clutch-to-clutch shift. Control strategies for upshifts and downshifts have been proposed, and a clutch torque controller has been designed for the torque phase on the basis of the proportional-integral-derivative (PID) control algorithm [108]. A simple and robust controller design, which is based on the actuator dynamics and the clutch slip dynamics and has consistent performance under different initial conditions, has been presented [109].

In terms of control strategies for the inertia phase, a combination of sliding mode control and adaptive feedback linearization has been used to achieve the desired reference tracking for the slip of the on-coming clutch [110]. A modelbased nonlinear gearshift controller was designed employing 
the back-stepping method to improve the shift quality of vehicles with DCT during the inertia phase [111]. A new nonlinear control method, especially applied in the inertia phase, was developed to deal directly with model parameter variation. It can be designed using a method involving three steps: steady-state control, reference dynamics feedforward control and PID feedback control [112]. The coordinated control of the engine and transmission has greatly improved the shift quality and clutch durability. This method is widely applied for the inertia phase of clutch-to-clutch shifts.

To compensate for the effects of build-to-build and lifecycle variations on shift quality, it is necessary to use adaptive control methods in shift control strategies. An adaptive system not only continuously monitors its own performance in relation to a given optimal condition but also modifies its own control parameters in a closed loop so as to approach the optimized performance. It has been experimentally demonstrated that clutch adaptive control strategies for the dry DCT not only reduce the level of jerk and frictional energy loss but also satisfy different starting intentions of the driver [113]. Kim [114] proposed an advanced shift controller that supervises the shift transients with adaptive compensation. The control input is updated through a learning process to adjust subsequent shifts on the basis of the continuous monitoring of shift performance and environment variations. Shi [115] proposed adaptive control strategies for the inertia phase and torque phase. Shift quality is evaluated by monitoring the speed deviation and time difference. Test results verify that the proposed control strategies improve the shift quality effectively.

DCT sets a benchmark for the shift time, giving the driver a quick response to the acceleration requirement. Control strategies have been developed for CVTs and ATs to compete with DCTs in terms of a shorter shift time. Jatco [116] used stepwise shift control to improve the acceleration feeling of CVT. BMW proposed control strategies for complex shift events to cover situations where the target gear is normally reached by passing through intermediate gear steps [117]. Through simultaneous actuation of various SEs, two sequential shifts are executed continuously. The overall shift duration can thus be reduced to achieve a fast shift performance. Aisin announced that its 10 -speed longitudinal AT has a faster shift than the benchmarked AT and DCT [53].

\section{Electrified Transmission Technology for HEVs/PHEVs/EVs}

This section reviews the progress of automotive transmissions for HEVs/PHEVs/EVs. The configuration design, energy management strategy, hybrid mode shifting control, EV transmission and distributed-drive EV are discussed separately.

\subsection{Configuration Design}

HEVs and PHEVs generally have one ICE and one or two EMs. Although the battery capacity differs between HEVs and PHEVs, the structural requirements for the drive system are the same. As previously described, HEV and PHEV transmissions can be simply divided into two types, namely add-on transmissions and DHTs [118], as shown in Fig. 13.

On the basis of conventional automotive transmissions, many manufacturers have developed a variety of hybrid configurations. ZF, Mercedes-Benz and Hyundai introduced P2 systems based on their own mature ATs. Jatco and Chery developed P2 systems based on CVTs. VW proposed a P2 hybrid system based on its own DCT. BYD also proposed a hybrid system based on DCT, but this is a P3 configuration.

Unlike the add-on solution, the DHT breaks the structural constraints of conventional transmissions. As the earliest DHT, the Toyota Hybrid System (THS) provided the direction for subsequent development in configuration design [119]. As technology advanced, Toyota introduced a fourthgeneration hybrid system, as shown in Fig. 14, and this system is now widely applied [120]. GM proposed two hybrid systems, namely Voltec-I and Voltec-II [121]. The secondgeneration system Voltec-II is shown in Fig. 14 and is used for the Volt, Malibu and Cadillac CT6. Compared with the THS, Voltec-II has more operating modes but more PGSs and SEs. Corun developed a hybrid system with multiple modes using an RGS and two SEs [122], as shown in Fig. 14. The above schemes are based on PGSs. In addition, companies such as Honda and SAIC have developed DHTs based on PGPs as shown in Fig. 14 [123, 124].

\subsection{Energy Management Strategy}

Energy management strategies for HEVs and PHEVs have been extensively discussed in the literature over the last decade. Figure 15 shows that energy management strategies can be generally classified into optimization-based control strategies and rule-based control strategies [125].

Optimization-based control strategies use analytical or numerical optimization algorithms to minimize the cost function regarding fuel consumption, emissions or driving performance. Optimization-based control strategies can be divided into global optimization and real-time optimization. If the optimization relies on knowledge of past or future power demands over a fixed and known driving cycle, a global optimal solution can be found. Because global optimization cannot be implemented directly for real-time energy management, it is referred to as non-causal. However, global optimization is useful in providing a control benchmark for designing rules or comparing with other control strategies. The strategies categorized under global optimization include linear programming, stochastic programming, dynamic pro- 
Add-on (Integrate EMs based on conventional automotive transmission ）

DHT (Designed for

HEV/PHEV)

\begin{tabular}{|c|c|c|c|c|c|c|}
\hline 䔍 & PO & P1 & P2 & P3 & P4 & $\begin{array}{l}\text { Represented by } \\
\text { Toyota THS system }\end{array}$ \\
\hline & and & 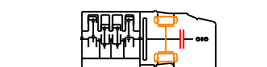 & 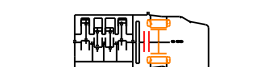 & 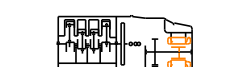 & & 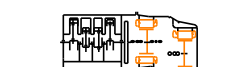 \\
\hline 氖 & $\begin{array}{l}\text { The EM is connected to } \\
\text { the crankshaft of the } \\
\text { engine through a belt. }\end{array}$ & $\begin{array}{l}\text { The EM is arranged between } \\
\text { the engine and the disconnect } \\
\text { clutch and is connected to the } \\
\text { engine crankshaft. }\end{array}$ & $\begin{array}{l}\text { The EM is arranged between } \\
\text { the disconnect clutch and the } \\
\text { transmission and is } \\
\text { connected with the } \\
\text { transmission input shaft. }\end{array}$ & $\begin{array}{l}\text { The EM is arranged in the } \\
\text { transmission or is } \\
\text { connected to the } \\
\text { transmission output shaft. }\end{array}$ & $\begin{array}{l}\text { EM is arranged on the } \\
\text { rear axle. }\end{array}$ & $\begin{array}{l}\text { Integration of PGSs, PGPs, } \\
\text { SEs and EMs. }\end{array}$ \\
\hline 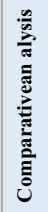 & $\begin{array}{l}\text { (1) Micro-hybrid system } \\
\text { (2) Small modifications } \\
\text { (3) Low fuel economy } \\
\text { (4) Low voltage }\end{array}$ & $\begin{array}{ll}\text { (1) } & \text { Mild-hybrid system } \\
\text { (2) Small modifications } \\
\text { (3) } \\
\text { (4) Low fuel economy } \\
\text { Lowigh voltage }\end{array}$ & $\begin{array}{ll}\text { (1) } & \text { Full-hybrid system } \\
\text { (2) Small modifications } \\
\text { (3) High fuel economy } \\
\text { (4) High voltage }\end{array}$ & $\begin{array}{ll}\text { (1) } & \text { Full-hybrid system } \\
\text { (2) } & \text { Large modifications } \\
\text { (3) High fuel economy } \\
\text { (4) }\end{array}$ & $\begin{array}{ll}\text { (1) } & \text { Full-hybrid system } \\
\text { (2) } & \text { Large modifications } \\
(3) & \text { High fuel economy } \\
\text { (4) } & \text { High voltage }\end{array}$ & $\begin{array}{l}\text { (1) Full-hybrid system } \\
\text { (2) New design } \\
\text { (3) High fuel economy } \\
\text { (4) High voltage }\end{array}$ \\
\hline
\end{tabular}

Fig. 13 Different types of hybrid transmission

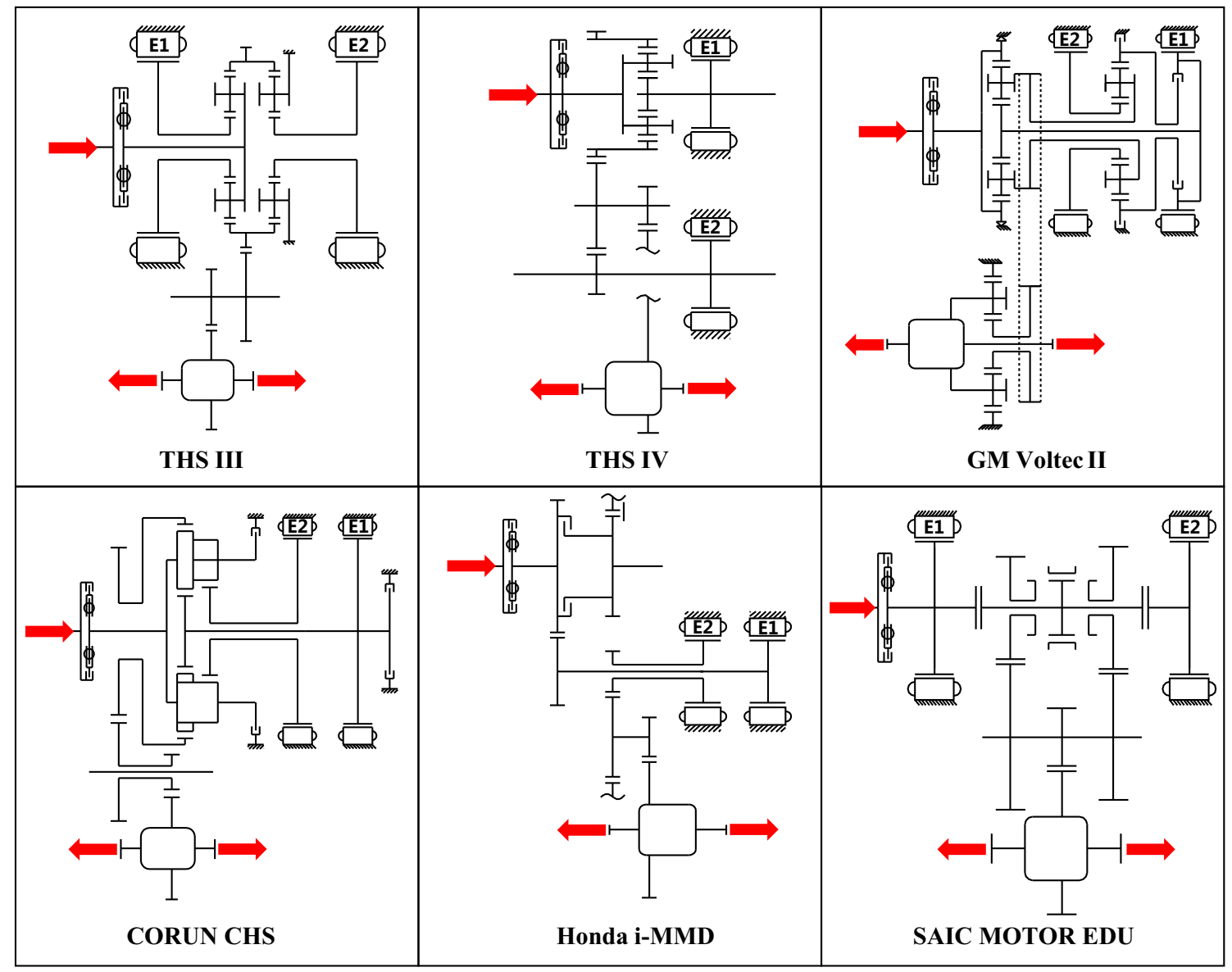

Fig. 14 DHTs of different companies

gramming, genetic algorithms, simulated annealing, game theory and optimal control theory. In contrast to global optimization, real-time optimization can be implemented online with an instantaneous cost function based on the system variable and measurement data. Real-time optimization consists of an equivalent fuel consumption minimization strategy, 
Fig. 15 Classification of energy management strategies

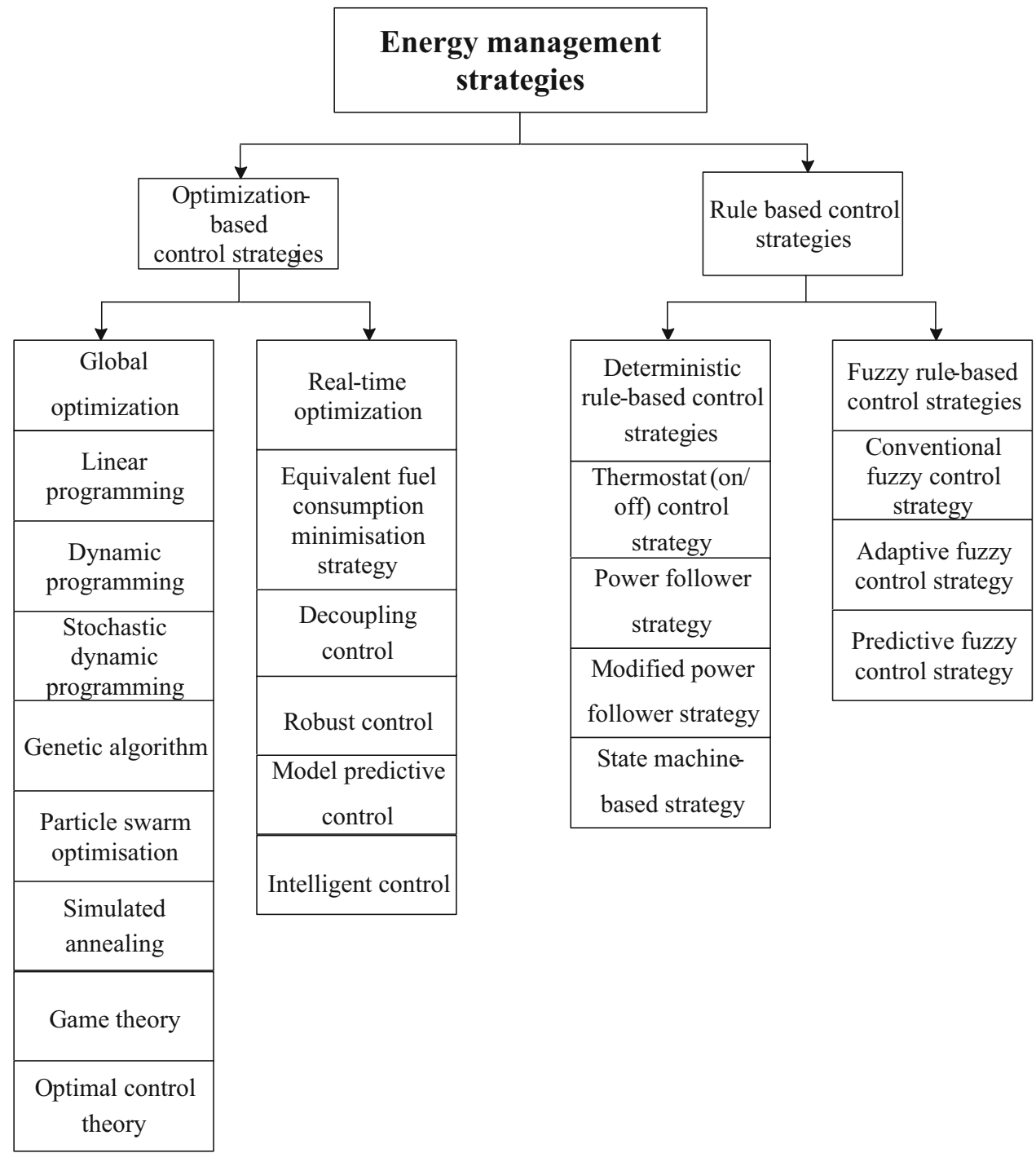

decoupling control, robust control, model predictive control and intelligent control.

Rule-based control strategies determine the control action at each moment by predefining a set of rules, which are designed in accordance with heuristics, intuition, human expertise, and mathematical models and, usually, without a priori knowledge of driving information. By means of simulation or calibration, the strategies are then precisely adjusted aiming at obtaining satisfactory fuel consumption results. Although rule-based control strategies are generally unable to guarantee optimality, their main advantage lies in their simplicity and effectiveness, which makes them easy to implement on actual HEVs and PHEVs. Rule-based control strategies are subcategorized into deterministic rule-based control strategies and fuzzy-rule-based control strategies. In deterministic rule-based control strategies, rules are designed via pre-computed look-up tables with the aid of enginebrake-specific fuel consumption. Such strategies can be further classified into thermostat (on/off) control strategies, power follower strategies, modified power follower strategies and state machine-based strategies. A fuzzy-rule-based control strategy, the advantages of which are its robustness to measurement noise and component variability along with its adaptation, is an extension of the deterministic rule-based control strategy. It is suitable for multi-domain, nonlinear, time-varying systems, such as HEVs. Fuzzy-rule-based control strategies can be further categorized into conventional, adaptive and predictive strategies.

Driving modes of HEVs and PHEVs depend on the transmission scheme. A mode shift map, which decides the timing and sequence of switching between modes, can be designed according to the abovementioned energy management strategies [126]. Unlike HEVs, PHEVs can be charged using outlets of the power grid. Additionally, PHEVs have larger battery capacity and a more powerful motor, which indicates that they offer a longer driving distance and an improved 
driving ability in electric-only mode than HEVs. This has given a new dimension to the energy management strategies as PHEVs can operate in both charge depleting (CD) and charge sustaining (CS) modes [127, 128]. Correspondingly, the transmission structure is modified for PHEV application; for example, an OWC is added to the THS to enable the vehicle to be driven using two motors [75].

\subsection{Hybrid Mode Shifting Control}

HEVs and PHEVs can run in different driving modes, among which typical modes are electric only, engine only, hybrid/electric assist, battery charging and regenerative braking. Shifts are made among these driving modes according to the vehicle and road conditions. Similar to gear shifting in conventional automotive transmissions, the mode transition in hybrid transmissions may result in negative customer perception of riding comfort and drivability if it is improperly controlled.

Engine start during mode transition is a major challenge for HEVs and PHEVs in terms of achieving good riding comfort. Some add-on hybrid transmissions retain a torque converter and improve their torsional damper to reduce the engine torque fluctuation from electric driving mode to hybrid driving mode. In control strategies, it is important to coordinate the engine torque, EM torque and clutch torque properly and precisely. Xu [129] proposed different engine-start control strategies with respect to riding comfort or a quick response under different starting conditions. To realize the smooth and fast engine start of a P2 PHEV, Yang [130] proposed a hierarchical mode transition control method based on a robust $H_{\infty}$ controller. Chen [131] developed a model reference controller with which to coordinate the engine, EM and clutch torque during mode transition for a series-parallel HEV. Zhao [132] developed a multistage optimal control strategy to determine the engine torque and clutch torque during mode transition. Therein, a sliding mode controller with anti-interference ability was designed to control the engine speed following the reference trajectory. Additionally, the model used to calculate feedforward control and $H_{\infty}$ robust feedback control was applied in the clutch synchronization phase. Kum [133] investigated theoretical performance limits and corresponding optimal control strategies that achieve a trade-off between drivability and a quick engine start. The results indicate that the optimal engine-start control strategy should choose a proper torque reserve and a corresponding clutch pressure that balances the engine-start time and torque responsiveness depending on the vehicle state and driver input.

It is noted that the engine-start performance of P2 hybrid transmission depends on the control of the disconnect clutch. Because the EM can provide a rapid torque response, it is precisely adjusted for both torque compensation and vehi- (a)

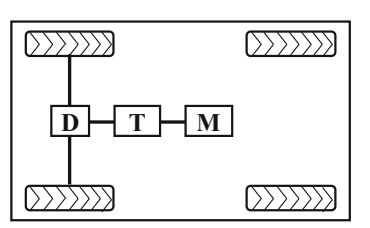

(c)

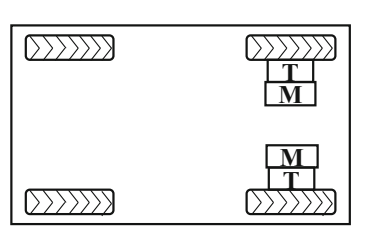

(b)

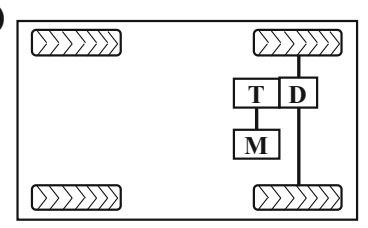

(d)

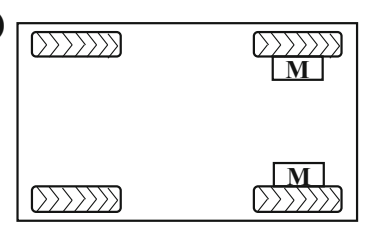

Fig. 16 Typical EV configurations: a central rear-wheel drive in the longitudinal layout; $\mathbf{b}$ central front-wheel drive in the transverse layout; c distributed front-wheel drive with transmission; d distributed frontwheel drive without transmission

cle driving during mode transition. For hybrid transmissions, such as THS and Voltec-II, there is no disconnect clutch. The engine can be directly cranked using the EM. Factors affecting the riding comfort of such transmissions have been concluded [134]. Proposals have been made for improving the riding comfort, e.g., varying the magnitude and frequency of the EM torque set points, the fuel ignition control and the intake air volume control. Wang [135] designed a coordinated control strategy for a power-split hybrid transmission and verified its effectiveness by simulation and experiment. Active damping control based on reference output shaft speed estimation and carrier torque estimation based on transmission kinematics and dynamics were applied to mitigate driveline oscillations and suppress torque fluctuation during engine cranking. Zeng [136] proposed a dynamic coordination control strategy based on model predictive control for a power-split hybrid electric bus, which is well suited to complex driving cycles.

\subsection{Single-Speed and Multi-speed EV Transmission}

The EV configuration determines the structure of the electric propulsion system and transmission. There are four typical EV configurations considering variations of the powertrain as seen in Fig. 16 [137], and any other EV configuration can be evolved from them. This section introduces the latest developments of EV transmission technologies in the central drive layout.

\subsubsection{Single-Speed Gearbox}

In comparison with the ICE, as seen in Fig. 17, the EM can emit maximum torque at low speeds, which eliminates the move-off elements for EVs. In addition, because the EM has a wider constant-power range and a vaster high-efficiency region than the ICE, fewer transmission gears are needed 
Fig. 17 Comparison of the characteristics of the EM and ICE (a)

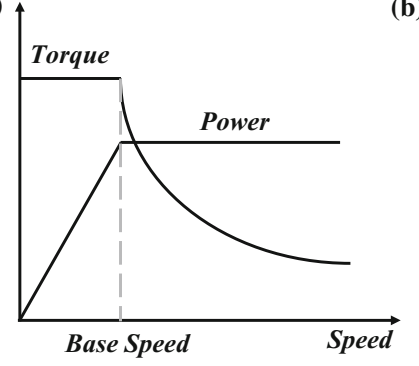

(b)

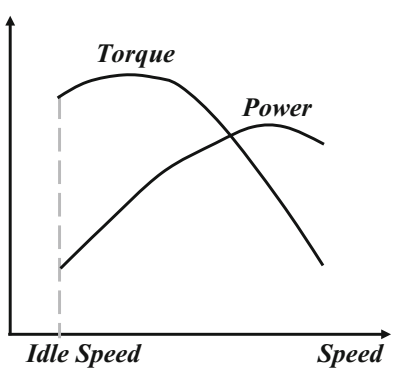

Table 1 Mass-produced EVs

\begin{tabular}{|c|c|c|c|c|c|c|c|}
\hline $\mathrm{EV}$ & Company & $\begin{array}{l}\text { Curb weight } \\
(\mathrm{kg})\end{array}$ & $\begin{array}{l}\text { Maximum } \\
\text { power }(\mathrm{kW})\end{array}$ & $\begin{array}{l}\text { Maximum } \\
\text { torque }(\mathrm{Nm})\end{array}$ & $\begin{array}{l}\text { Maximum } \\
\text { vehicle speed } \\
(\mathrm{kph})\end{array}$ & $\begin{array}{l}\text { Maximum } \\
\text { motor speed } \\
(\mathrm{rpm})\end{array}$ & Gear ratio \\
\hline Model S & Tesla & 2239 & $\begin{array}{l}581 \\
\quad \text { (combined) }\end{array}$ & $\begin{array}{l}1250 \\
\text { (combined) }\end{array}$ & 249 & $\begin{array}{l}16,000 \text { (rear } \\
\text { motor) }\end{array}$ & $\begin{array}{r}9.73 \text { (rear } \\
\text { gearbox) }\end{array}$ \\
\hline Bolt & Chevrolet & 1625 & 150 & 360 & 140 & 8810 & 7.05 \\
\hline Leaf & Nissan & 1557 & 110 & 320 & 140 & 10,390 & 7.937 \\
\hline i3 & BMW & 1298 & 125 & 250 & 150 & 11,400 & 9.7 \\
\hline Zoe & Renault & 1468 & 68 & 220 & 135 & 12,000 & 9.32 \\
\hline EC180 & BJEV & 1050 & 30 & 140 & 100 & 8000 & 6.71 \\
\hline
\end{tabular}

to meet traction and energy-saving demands. Furthermore, the torque ripple of various EMs is much smaller than that of the ICE and the torsion damper can correspondingly be abolished for EVs. To reduce the volume and costs of the powertrain and to shorten the development cycle, considering the above advantages of the EM, most mass-produced EVs use a single-speed gearbox to adapt the traction available to the power required as seen in Table 1. Obviously, greater torque with a large gear ratio is required to satisfy driving performance demands, and higher-speed EMs have accordingly been developed to meet the maximum vehicle speed.

Figure 18 shows a typical structure of the EV powertrain with a single-speed gearbox [138], which uses two PGPs to realize a total gear ratio of 7.05. Such an integrated and coaxial configuration not only minimizes the volume of the powertrain but also makes the most of the oil pump to lubricate and cool both the EM and gearbox. Most other mass-produced single-speed gearboxes have generally adopted PGPs considering costs and efficiency; however, PGSs provide a larger gear ratio to lower the maximum torque of the EM. Figure 19 shows that combining a PGS with a PGP, ZF's EV drive 1 realizes a total gear ratio of 16 , which reduces the maximum EM torque to $125 \mathrm{Nm}$ but raises the maximum EM speed to 21,000 rpm [139].

\subsubsection{Multi-speed Transmission}

To improve the dynamic performance and economy of an $\mathrm{EV}$ or to reduce the maximum EM torque and the max-

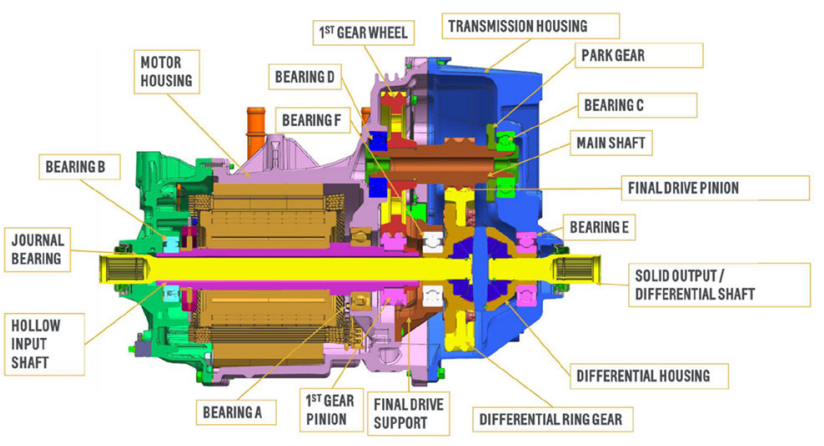

Fig. 18 Structure of the Chevrolet Bolt EV powertrain. (Reproduced with permission from [138])

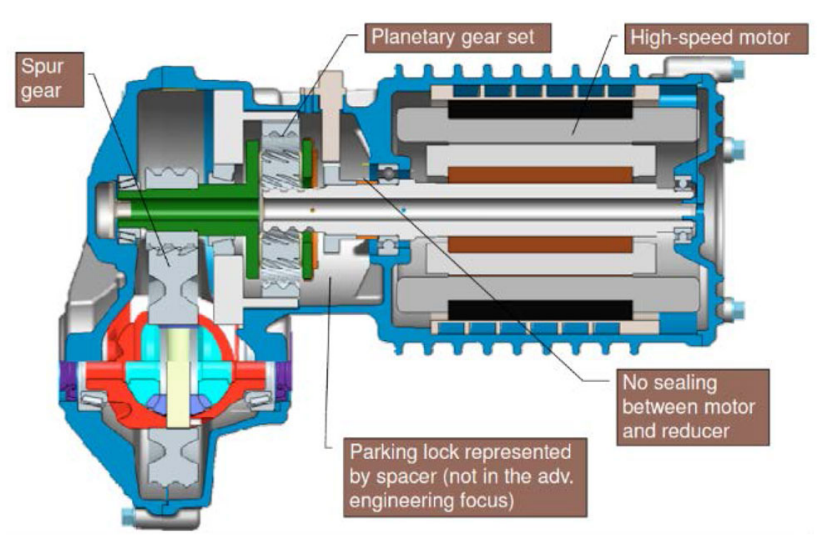

Fig. 19 Structure of ZF's EV drive 1. (Reproduced with permission from [139]) 


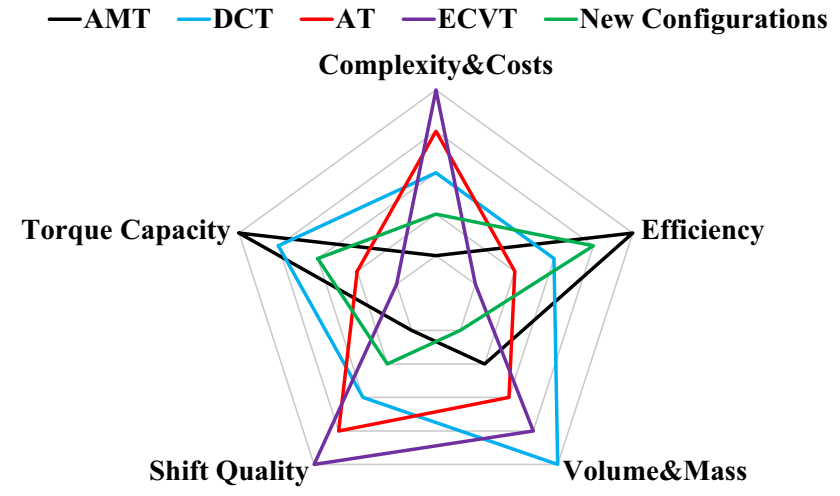

Fig. 20 Comparison of different multi-speed transmission configurations for EVs

imum EM speed and thus reduce the size and cost of an EM, much research has been conducted on the multi-speed transmission for EVs [140-142]. Research shows that a twospeed transmission with optimized gear ratios and shifting map not only reduces energy consumption by about $5-16 \%$ but also improves the dynamic performance by nearly $20 \%$ and increases the maximum speed by nearly $30 \%$. However, a continued increase in transmission speeds will not reduce the energy consumption appreciably for light passenger cars but increase the costs. In addition, the CVT with a rational gear ratio range can improve the efficiency of the EM maximally but results in a complex structure. In summary, it is commonly recognized that two speeds and two-four speeds are, respectively, the best choices for passenger cars and commercial vehicles in terms of costs, transmission efficiency and EM efficiency.

Most multi-speed transmission technologies for EVs have been developed from the conventional transmission for ICE vehicles. Their main configurations are the AMT [143, 144], DCT [145, 146], AT [147, 148], electric continuously variable transmission (ECVT) [149] and other new configurations $[150,151]$. Figure 20 shows that the AMT is the most efficient and least expensive but has the poorest shift quality. The ECVT and AT have the best shift quality but are expensive and less efficient. Usually, to balance the tradeoff between costs and performance, new configurations are designed. Figure 21 shows five typical structures of different multi-speed transmission configurations for EVs. The AMT uses an actuating motor and a synchronizer to shift but has a power interruption [152]. The DCT and AT both adopt a clutch-to-clutch shifting control strategy to realize power shifts [146, 147]. Through the coordinated control of the traction motor and speed motor, the ECVT can achieve both differential control and torque vectoring control of two shafts [149]. The new configuration uses a centrifugal clutch and brake band to realize uninterrupted shifts [150].

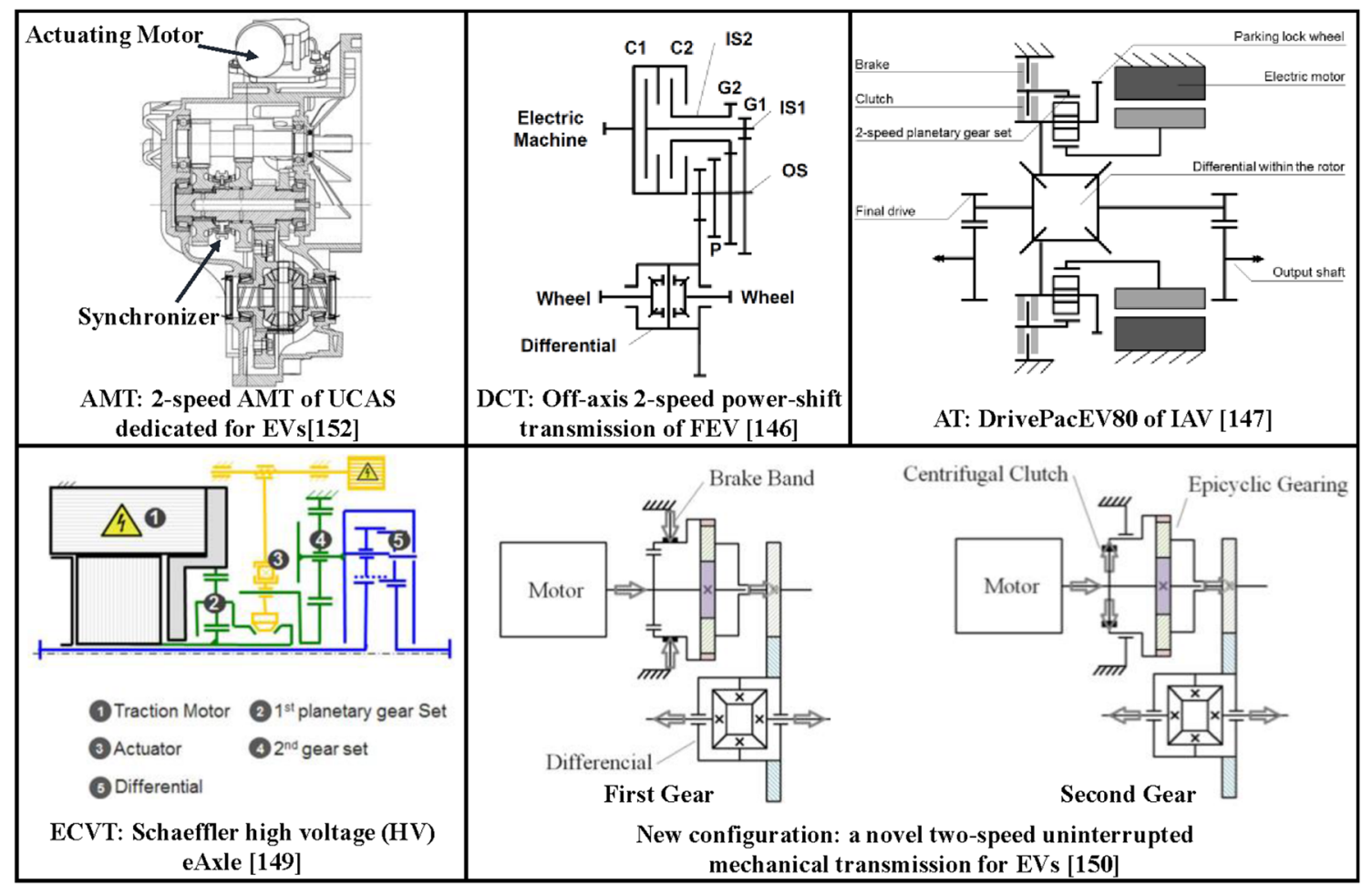

Fig. 21 Typical structures of different multi-speed transmission configurations for EVs 


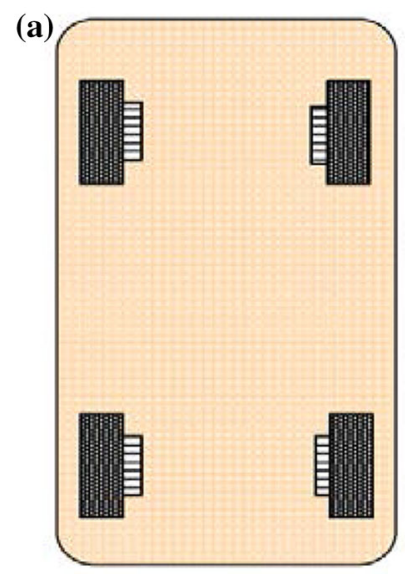

(b)

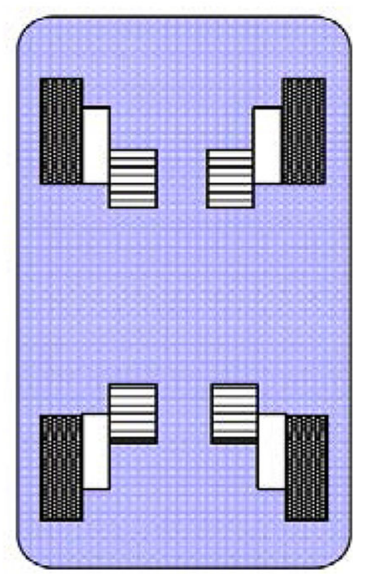

Fig. 22 Two typical types of distributed-drive EVs: a in-wheel motors; b motors with gearboxes

\subsection{Distributed Electric Drive}

In a distributed electric drive, the wheels are directly driven by electric motors. Figure 22 shows that, generally, there are two typical types of distributed-drive EVs [153]. In the first type, the motors are mounted in the wheel hubs. In the second type, a gearbox is used between the electric motor and wheel. In some practical cases, there are only two electric motors instead of four, with the motors directly driving the front wheels or rear wheels.

The powertrain of a traditional vehicle consists of an engine, clutch, transmission, shaft or two shafts, and differential. Compared with the traditional powertrain, the distributed-drive electric powertrain has several advantages $[154,155]$ :

1. Simpler vehicle architecture, vehicle design and packaging;

2. Higher drive efficiency and less vehicle mass;

3. A more precise and faster response to the torque demand;

4. Higher regenerated brake energy and less energy consumption.

Because there are no gearboxes, the in-wheel-motordrive EVs have the potential to save energy compared with

Fig. 23 Three commercial in-wheel motors and motor-hub wheels on the market: a e-Traction; b Protean; c Elaphe (a)

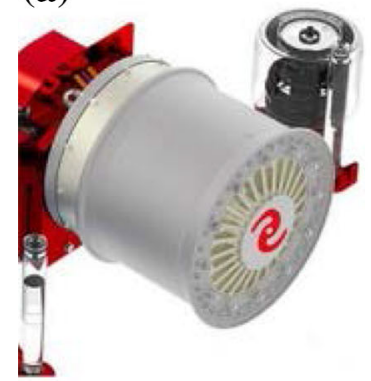

the counterpart of motor-gearbox-drive EVs. However, the design of in-wheel motors is more challenging in terms of the size control and thermal management. After decades of development, there are several well-recognized in-wheel motors and motor-hub wheels on the current market. Figure 23 depicts three examples, namely e-Traction, Protean and Elaphe. We see that all of them are compact.

Owing to the benefits of well-developed in-wheel motors and motor-hub wheels, the integration and dynamics control of distributed-drive EVs have attracted attention from researchers over the past two decades. Table 2 shows that different prototypes of distributed-drive EVs have been developed in Japan, the USA, China, Europe and Canada. It has been reported that distributed-drive EVs can be represented by an over-actuator system $[156,157]$. The motion control of longitudinal and lateral directions is then relatively difficult but flexible. Considerable methodologies have been applied to motion control for the purpose of improving safety, agility, handling and fuel economy [158-165]. Another hot research topic of distributed-drive EVs is how to reduce the effect of the unsprung mass on the vehicle dynamics and control $[166,167]$. Research and improvements of the technique are ongoing for the industrialization of distributed-drive EVs. Distributed-drive EVs will be widely used on the road in the near future.

\section{Summary and Outlook}

Over the past two decades, automotive transmissions have evolved with greater speed numbers, an expanded ratio spread and improved efficiency and shift quality. DCTs were launched onto the market in 2003, offering both high efficiency and a fast shift and thus promoting the development of ATs and CVTs. Novel ATs with four or five DOFs were released continuously with higher efficiency and better shift quality. The torque capacity and efficiency of CVTs have also been improved. It is clear that ATs, DCTs and CVTs will coexist in the passenger car market in the future. In the commercial vehicle market, AMTs and ATs will be dominant. The increase in the speed number of conven- (b)

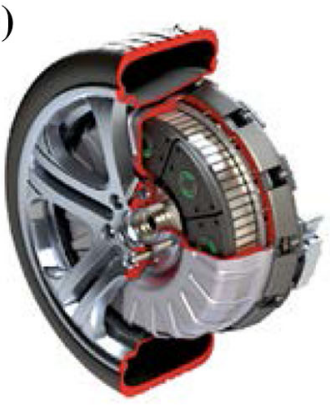

(c)

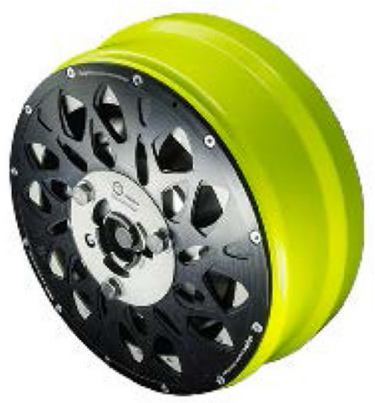


Table 2 Worldwide research groups with prototypes of distributeddrive EVs

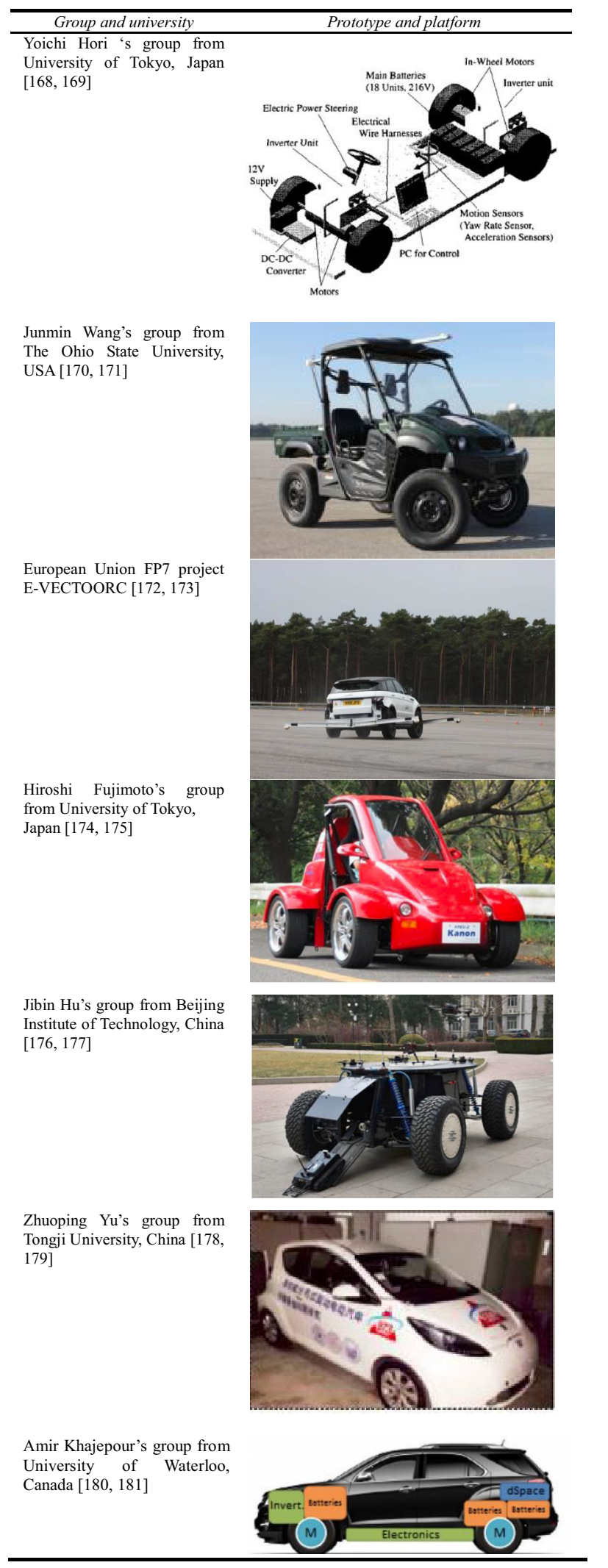

tional automotive transmissions has almost come to an end. In the future, the focus will remain on the optimization of the transmission's mechanical and hydraulic systems in terms of efficiency, $\mathrm{NVH}$ in terms of driving comfort and shifting strategy and control technology in terms of shift quality.

It is evident that the development trend of automotive transmissions is electrification. For hybrid transmissions, add-on solutions and DHT solutions coexist on the market. However, it is believed that DHT has a bright future with the increasing volume of hybrid vehicles. The energy management strategy is the key for realizing fuel savings of HEVs and PHEVs. With the development of electronics and computation capability, the energy management strategy will be optimized in real time according to the route information accessed via the Global Positioning System. Mode shifting control will be improved to make the shift event imperceptible to the driver.

The single-speed gearbox currently dominates the EV market. In the future, two- or three-speed transmission will occupy a certain EV market share, lowering the torque and speed requirements of the EM. Meanwhile, EV transmission will be integrated with the EM and power electronics step by step from a modular design to a semiintegrated design, an integrated design and finally a fully integrated design. The distributed electric drive will first enter the market of commercial vehicles (e.g., buses and military vehicles) before penetrating the market of passenger cars.

Acknowledgements The authors acknowledge the support of Beijing Key Laboratory for High-efficient Power Transmission and System Control of New Energy Resource Vehicle. This work is financially supported by the National Key R\&D Program of China "Development and Vehicle Integration of Cost-effective Commercial Vehicle Hybrid System" (Grant No. 2018YFB0105900). The authors are grateful for the contributions of Dr. Yunjiang Cheng and postgraduate students Hanqiao Sun, Xiaoxiao Wu, Junbin Lai, Songlin Li, Lei Shi and Huize Ding.

Open Access This article is distributed under the terms of the Creative Commons Attribution 4.0 International License (http://creativecomm ons.org/licenses/by/4.0/), which permits unrestricted use, distribution, and reproduction in any medium, provided you give appropriate credit to the original author(s) and the source, provide a link to the Creative Commons license, and indicate if changes were made.

\section{References}

1. Yan, Q.D., Li, S.L., Yao, S.W.: Analysis method of planetary speed-shifting mechanism based on graph theory. J. Jilin Univ. Eng. Technol. Ed. 40(4), 1029-1033 (2010)

2. Tan, G.H.: A study on the development of mechanical drive of vehicle transmission. J. Zhuzhou Inst. Technol. 20(4), 49-52 (2006)

3. Liu, X.J.: The multi-member planetary gearing layout analysis and design. J. Beijing Inst. Technol. Engl. Ed. 1, 74-91 (1984) 
4. Dong, P., Liu, Y.F., Tenberge, P., et al.: Design and analysis of a novel multi-speed automatic transmission with four degrees-offreedom. Mech. Mach. Theory 108, 83-96 (2017)

5. Wan, Y.Q., Wang, W.Q.: The development and application of the multi-freedom degrees planetary gear box scheme synthetical. Mach. Des. 15(10), 7-9 (1998)

6. Xie, T.L.: Topology synthesis of planetary gear train with multiple degrees of freedom for vehicle. Beijing Institute of Technology. Dissertation (2015)

7. Liu, T.L.: The synthetical method of multi-speed planetary gearbox with three degrees of freedom by means of computer. Veh. Power Technol. 1, 51-58 (1984)

8. Radzevich, S.P.: Theory of gearing: kinetics, geometry, and synthesis. CRC Press, Boca Raton (2013)

9. Wan, Y.Q.: The theory of computer aided design of multi-DOF planetary gearbox scheme. Mach. Des. Res. 3, 13-19 (1984)

10. Tian, N.S., Zhou, S.R.: A research on the optimizing method of the scheme of multivariant planetary transmission. J. Railw. Sci. Eng. 14(2), 19-26 (1996)

11. Liu, B.D., Li, J., Li, L.Z.: Combined solution method for optimization of multi-degree-of-freedom planetary gearbox. Veh. Power Technol. 1, 12-24 (1987)

12. Kahraman, A., Ligata, H., Kienzle, K., et al.: A kinematics and power flow analysis methodology for automatic transmission planetary gear trains. J. Mech. Des. 126(6), 1071-1081 (2004)

13. Inalpolat, M., Kahraman, A.: A dynamic model to predict modulation sidebands of a planetary gear set having manufacturing errors. J. Sound Vib. 329(4), 371-393 (2010)

14. Xu, A.F., Jia, J.M., Liu, N.: Study on the gearing scheme of planetary gear train based on improved lever analogy. J. Mil. Transp. Univ. 16(7), 91-95 (2014)

15. Wang, Z., Zhang, J., Zhang, Y.: A novel graphic characteristic based method for topology analysis in substations and power plants. Trans. China Electrotech. Soc. 27(2), 255-260 (2012)

16. Tsai, L.W.: An application of the linkage characteristic polynomial to the topological synthesis of epicyclic gear trains. J. Mech. Transm. Autom. Des. 109(3), 329-336 (1987)

17. Dobrjanskyj, L., Freudenstein, F.: Some applications of graph theory to the structural analysis of mechanisms. J. Eng. Ind. 89(1), 153-158 (1967)

18. Buchsbaum, F., Freudenstein, F.: Synthesis of kinematic structure of geared kinematic chains and other mechanisms. J. Mech. 5(3), 357-392 (1970)

19. Kurth, F.: Efficiency determination and synthesis of complexcompound planetary gear transmissions. Technische Universität München. Dissertation (2012)

20. Troha, S., Lovrin, N., Milovancevic, M.: Selection of the twocarrier shifting planetary gear train controlled by clutches and brakes. Trans. Famena 36(3), 1-12 (2012)

21. Arnaudov, K., Karaivanov, D.: Higher compound planetary gear trains. Proc. VDI Berichte 1904(1), 327-344 (2005)

22. Li, S.1.: Computer aided design of planetary transmission scheme based on graph theory. Beijing Institute of Technology. Dissertation (2009)

23. Gumpoltsberger, G.: Systematische synthese und bewertung von mehrgängigen planetengetrieben. Chemnitz University of Technology. Dissertation (2007)

24. Ma, M.Y., Liu, Y.F., Xu, X.Y., et al.: Automatic detection of geometric compatibility for planetary gear train. Autom. Eng. 36(5), 603-607 (2014)

25. Ma, M.Y., Liu, Y.F., Xu, X.Y., et al.: Structure synthesis of 4-DOF planetary transmission. J. Mech. Transm. 38(9), 34-38 (2014)

26. Yuan, S.H., Liu, H., Peng, Z.X., et al.: Analysis of the compound split transmission based on the four-port power split device. J. Beijing Inst. Technol. Engl. Ed. 21(1), 50-57 (2012)
27. Liao, Y.G., Chen, M.Y.: Analysis of multi-speed transmission and electrically continuous variable transmission using lever analogy method for speed ratio determination. Adv. Mech. Eng. 9(8), 1-12 (2017)

28. Liu, J., Peng, H.: Modeling and control of a power-split hybrid vehicle. IEEE Trans. Control Syst. Technol. 16(6), 1242-1251 (2008)

29. Zhuang, W.C., Zhang, X.W., Zhao, D., et al.: Optimal design of three-planetary-gear power-split hybrid powertrains. Int. J. Autom. Technol. 17(2), 299-309 (2016)

30. Zhuang, W.C., Zhang, X.W., Zhao, D., et al.: Rapid configuration design of multiple-planetary-gear power-split hybrid powertrain via mode combination. IEEE/ASME Trans. Mechatron. 21(6), 2924-2934 (2016)

31. Zhang, X.W., Peng, H., Sun, J., et al.: Automated modeling and mode screening for exhaustive search of double-planetary-gear power split hybrid powertrains. In: Proceedings of the ASME 7th Annual Dynamic Systems and Control Conference, San Antonio, USA (2014)

32. Tsai, L.W., Schultz, G.: A motor-integrated parallel hybrid transmission. J. Mech. Des. 126(5), 889-894 (2004)

33. Dagci, O.H., Peng, H., Grizzle, J.W.: Hybrid electric powertrain design methodology with planetary gear sets for performance and fuel economy. IEEE Access 6, 9585-9602 (2018)

34. Qin, Z., Luo, Y., Li, K., et al.: A new powertrain design approach for power-split hybrid tracked vehicles. In: Proceedings of the ASME 2017 Dynamic Systems and Control Conference, Tysons Corner, USA (2017)

35. Qin, Z., Luo, Y., Li, K., et al.: Optimal design of a novel hybrid electric powertrain for tracked vehicles. Energies 10(12), 2141-2165 (2017)

36. Zhuang, W., Zhang, X., Peng, H., et al.: Simultaneous optimization of topology and component sizes for double planetary gear hybrid powertrains. Energies 9(6), 411-427 (2016)

37. Dagci, O.H., Peng, H.: A method for the exploration of hybrid electric powertrain architectures with two planetary gearsets. SAE Int. J. Altern. Powertrains 5(1), 94-108 (2016)

38. Ngo, H.T., Yan, H.S.: Configuration synthesis of parallel hybrid transmissions. Mech. Mach. Theory 97, 51-71 (2016)

39. Ngo, H.T., Yan, H.S.: Novel configurations for hybrid transmissions using a simple planetary gear train. J. Mech. Robot. 8(2), $1-10$ (2016)

40. Hellenbroich, G., Ruschhaupt, J.: Innovative xDCT family of FEV-extremely compact 7 and 10 speed DCTs. In: Proceedings of Symposium on International Automotive Technology, India (2013)

41. Leesch, M.: Beitrag zur systematischen synthese und bewertung von doppelkupplungsgetrieben. Chemnitz University of Technology. Dissertation (2012)

42. Yue, J.H., Li, H.: Parameter optimization of 7 shafts transmission system based on MATLAB. J. Mech. Transm. 39(5), 80-84 (2015)

43. Ma, M.Y., Liu, Y.F., Xu, X.Y., et al.: Selection of shifting element design based on genetic algorithm. J. Beijing Univ. Aeronaut. Astronaut. 40(10), 1327-1377 (2014)

44. Rossetti, A., Macor, A.: Multi-objective optimization of hydromechanical power split transmissions. Mech. Mach. Theory 62, 112-128 (2013)

45. Xu, X.Y., Chen, Z.F., Liu, Y.J., et al.: Enumerative optimization procedure for the gear train optimization problem of a twospeed dedicated electric transmission. Energies 10(9), 1362-1385 (2017)

46. Chen, Z.F.: Critical technologies of the mechatronic system of a two-speed automatic transmission dedicated for electric vehicles. Beihang University. Dissertation (2018) 
47. Zhang, X., Peng, H., Sun, J.: A near-optimal power management strategy for rapid component sizing of multimode power split hybrid vehicles. IEEE Trans. Control Syst. Technol. 23(2), 609-618 (2015)

48. Koguchi, T.: Evolution of a CVT with an auxiliary gearbox. In: Proceedings of the 9th International CTI Symposium. Shanghai, China (2015)

49. Scherer, H.: ZF 6-speed automatic transmission for passenger cars. SAE Technical Paper 2003-01-0596 (2003)

50. Dick, A., Greiner, J., Locher, A., et al.: Optimization potential for a state of the art 8-Speed AT. SAE Int. J. Passeng. Cars Mech. Syst. 6(2), 899-907 (2013)

51. Uozumi, S., Taniguchi, T., Tsukamoto, K., et al.: AISIN AW new six-speed automatic transmission for RWD vehicles. SAE Technical Paper 2004-01-0652 (2004)

52. Kondo, M., Hasegawa, Y., Takanami, Y., et al.: Toyota AA80E 8-speed automatic transmission with novel powertrain control system. SAE Technical Paper 2007-01-1311 (2007)

53. Suzuki, T., Sugiura, H., Niinomi, A., et al.: New RWD 10 speed automatic transmission for passenger vehicles. SAE Int. J. Engines 10(2), 695-700 (2017)

54. Greiner, J., Doerr, C., Nauerz, H., et al.: The new "7G-TRONIC" of Mercedes-Benz: innovative transmission technology for better driving performance, comfort and fuel economy. SAE Technical Paper 2004-01-0649 (2004)

55. Doerr, C., Homm, M., Indlekofer, G.: The new automatic transmission 9G-Tronic from Mercedes-Benz. In: Proceedings of the 12th International CTI Symposium-Automotive Transmissions and HEV and EV Drives, Berlin, Germany, pp. 153-160 (2013)

56. Hart, J.M.: General motors rear wheel drive eight speed automatic transmission. SAE Int. J. Passeng. Cars Mech. Syst. 7(1), 289-294 (2014)

57. Brehmer, M., Diosi, G., Haupt, J.: 10-gear automatic transmission. Patent US 13/852589 (2013)

58. Kluemper, S.: Allison's new 9-speed medium duty fully automatic transmission. In: Proceedings of the 12th International CTI Symposium, Michigan, USA (2018)

59. Gaertner, L., Ebenhoch, M.: The ZF automatic transmission 9HP48 transmission system, design and mechanical parts. SAE Int. J. Passeng. Cars Mech. Syst. 6(2), 908-917 (2013)

60. Katou, N., Taniguchi, T., Tsukamoto, K., et al.: AISIN AW new six-speed automatic transmission for FWD vehicles. SAE Technical Paper 2004-01-0651 (2004)

61. Aoki, T., Kato, H., Kato, N., et al.: The world's first transverse 8-speed automatic transmission. SAE Technical Paper 2013-01$1274(2013)$

62. Fischer, H.C., Diaz-Theilmann, A., Lecomte, O., et al.: Third generation of Global FWD 6-speed Automatic Transmission (GF6). In: Proceedings of International VDI Congress, Friedrichshafen, Germany, pp. 299-316 (2014)

63. Bockenstette, C.M., Marin, C.E., Otanez, P.G., et al.: Nine speed transmission with latching mechanism. Patent US 20140378266 (2014)

64. Renneker, C.: Ford's "Hat Trick": 3 new 8-speed automatic transmissions. In: Proceedings of the 12th International CTI Symposium, Michigan, USA (2018)

65. Suigino, S., Muramatsu, I.: Honda's 10-speed automatic transmission. In: Proceedings of the 12th International CTI Symposium, Michigan, USA (2018)

66. Fu, Y.X., Yang, Y., Xu, X.Y., et al.: A new archetype of automatic transmission. SAE Technical Paper 2011-01-1429 (2011)

67. Schreiber, W., Rudolph, F., Becker, V.: The new dual clutch gearbox from Volkswagen. ATZ Worldw. 105(11), 2-6 (2003)

68. Hadler, J., Metzner, F., Schäfer, M., et al.: The seven-speed dual clutch transmission from Volkswagen. ATZ Worldw. 110(6), 26-33 (2008)
69. Hadler, J., Schäfer, M., Gröhlich, H., et al.: DQ500- the new Volkswagen seven-speed dual-clutch gearbox for high torques. In: Proceedings of the 18th Aachen Colloquium Automobile and Engine Technology, Aachen, Germany (2009)

70. Machida, S., Yagi, N., Miyata, K., et al.: Development of 8-speed DCT with torque converter for midsize vehicles. Honda R\&D Tech. Rev. 26, 119-125 (2014)

71. Donges, A., Jauch, F., Sibla, C.: $\mathrm{CO}_{2}$ potentials for further development of the 8HP transmission kit. In: Proceedings of the 16th International CTI Symposium, Berlin, Germany (2017)

72. Schulz, J.: Separating springs for active separation of the friction plates in wet clutch systems. In: Proceedings of the 10th International CTI Symposium and Exhibition, Berlin, Germany (2011)

73. Naunheimer, H., Bertsche, B., Ryborz, J., et al.: Automotive transmissions: fundamentals, selection, design and application. Springer, Berlin (2011)

74. Dörr, C., Kalczynski, H., Rink, A., et al.: Nine-speed automatic transmission 9G-Tronic by Mercedes-Benz. ATZ Worldw. 116(1), 20-25 (2014)

75. Ichikawa, S., Takeuchi, H., Fukuda, S., et al.: Development of new plug-in hybrid system for compact-class vehicle. SAE Int. J. Altern. Powertrains 6(1), 95-102 (2017)

76. Iwasawa, T., Momoi, M., Hayakawa, K., et al.: Development of new variator system for the Jatco CVT7 W/R. In: Proceedings of 5th International CTI Symposium, Shanghai, China (2016)

77. Dong, P., Liu, Y.F., Xu, X.Y.: A method of applying two-pump system in automatic transmissions for energy conservation. Adv. Mech. Eng. 7(7), 1-11 (2015)

78. Liu, Y.F., Dong, P., Liu, Y., et al.: Design and application of electric oil pump in automatic transmission for efficiency improvement and start-stop function. J. Central South Univ. 23(3), 570-580 (2016)

79. Liu, Y., Wang, S.H., Dong, P., et al.: Dynamic analysis and control of an automatic transmission for start-stop function and efficiency improvement. Math. Probl. Eng. 2015, 1-13 (2015)

80. Li, R.F., Wang, J.J.: Geared system dynamic-vibration, shock and noise. China Science Press, Beijing (1997)

81. Houser, D.R., Ueda, Y., Harianto, J.: Determining the source of gear whine noise. Gear Solut. 2, 17-22 (2004)

82. Smith, J.D.: Gear Noise and Vibration. Marcel Dekker, New York (2003)

83. Lei, Y.L., Hou, L.G., Fu, Y., et al.: Transmission gear whine control by multi-objective optimization and modification design. SAE Technical Paper 2018-01-0993 (2018)

84. Bellomo, P., De Vito, N., Lang, C.H., et al.: In depth study of vehicle powertrains to identify causes of loose components rattle in transmissions. SAE Technical Paper 2002-01-0702 (2002)

85. Jadhav, S.M.: Powertrain NVH analysis including clutch and gear dynamics. SAE Technical Paper 2014-01-1680 (2014)

86. Galvagno, E., Guercioni, G.R., Vigliani, A.: Sensitivity analysis of the design parameters of a dual-clutch transmission focused on NVH performance. SAE Technical Paper 2016-01-1127 (2016)

87. Crowther, A.R., Zhang, N., Singh, R.: Development of a clunk simulation model for a rear wheel drive vehicle with automatic transmission. SAE Technical Paper 2005-01-2292 (2005)

88. Wang, J., Lei, Y., Ge, A., et al.: Noise quality analysis and metrics development under transient shifting condition. SAE Int. J. Passeng. Cars Mech. Syst. 1(1), 250-257 (2008)

89. Chaturvedi, G.K., Thomas, D.W.: Bearing fault detection using adaptive noise cancelling. J. Mech. Des. 104(2), 280-289 (1982)

90. Yue, G., Niu, W., Zhao, J., et al.: Gear whine resolution by tooth modification and multi-body dynamics analysis. SAE Technical Paper 2016-01-1061 (2016)

91. Bile, Y., Gondhalekar, A., Kumbhar, M.: Studies on neutral gear rattle in early stage design. SAE Technical Paper 2013-26-0109 (2013) 
92. Campbell, B., Stokes, W., Steyer, G., et al.: Gear noise reduction of an automatic transmission through finite element dynamic simulation. SAE Technical Paper 971966 (1997)

93. Montanari, M., Ronchi, F., Rossi, C., et al.: Control and performance evaluation of a clutch servo system with hydraulic actuation. Control Eng. Pract. 12(11), 1369-1379 (2004)

94. Watson, M., Byington, C., Edward, D., et al.: Dynamic modeling and wear-based remaining useful life prediction of high power clutch systems. Tribol. Trans. 48(2), 208-217 (2005)

95. Walker, P.D., Zhu, B., Zhang, N.: Nonlinear modeling and analysis of direct acting solenoid valves for clutch control. J. Dyn. Syst. Meas. Contr. 136(5), 1-9 (2014)

96. Liu, Z., Gao, J., Zheng, Q.: Robust clutch slip controller design for automatic transmission. Proc. Inst. Mech. Eng. D J. Autom. Eng. 225(8), 989-1005 (2011)

97. Van de Ven, J.D., Cusack, J.: Synthesis and baseline testing of a digital pulse-width-modulated clutch. Mech. Mach. Theory 78(78), 81-91 (2014)

98. Dutta, A., Depraetere, B., Ionescu, C., et al.: Comparison of twolevel NMPC and ILC strategies for wet-clutch control. Control Eng. Pract. 22, 114-124 (2014)

99. Dutta, A., Zhong, Y., Depraetere, B., et al.: Model-based and model-free learning strategies for wet clutch control. Mechatronics 24(8), 1008-1020 (2014)

100. Meng, F., Chen, H.Y., Zhang, T., et al.: Clutch fill control of an automatic transmission for heavy-duty vehicle applications. Mech. Syst. Signal Process. 64-65, 16-28 (2015)

101. Pinte, G., Depraetere, B., Symens, W., et al.: Iterative learning control for the filling of wet clutches. Mech. Syst. Signal Process. 24(7), 1924-1937 (2010)

102. Gao, B.Z., Chen, H., Hu, Y.F., et al.: Nonlinear feedforward-feedback control of clutch-to-clutch shift technique. Veh. Syst. Dyn. 49(12), 1895-1911 (2011)

103. Gao, B.Z., Chen, H., Li, J., et al.: Observer-based feedback control during torque phase of clutch-to-clutch shift process. Int. J. Veh. Des. 58(1), 93-108 (2012)

104. Chen, L., Xi, G., Yin, C.L.: Model referenced adaptive control to compensate slip-stick transition during clutch engagement. Int. J. Autom. Technol. 12(6), 913-920 (2011)

105. Dutta, A., Ionescu, C.M., De Keyser, R., et al.: Robust and two-level (nonlinear) predictive control of switched dynamical systems with unknown references for optimal wet-clutch engagement. Proc. Inst. Mech. Eng. I J. Syst. Control Eng. 228(4), 233-244 (2013)

106. Song, X., Sun, Z.: Pressure-based clutch control for automotive transmissions using a sliding-mode controller. IEEE/ASME Trans. Mechatron. 17(3), 534-546 (2012)

107. Watechagit, S.: Modeling and estimation for stepped automatic transmission with clutch-to-clutch shift technology. University of Ohio State. Dissertation (2004)

108. Liu, Y.G., Qin, D.T., Jiang, H., et al.: Shift control strategy and experimental validation for dry dual clutch transmissions. Mech. Mach. Theory 75, 41-53 (2014)

109. Van Berkel, K., Hofman, T., Serrarens, A., et al.: Fast and smooth clutch engagement control for dual-clutch transmissions. Control Eng. Pract. 22, 57-68 (2014)

110. Mishra, K.D., Srinivasan, K.: Robust nonlinear control of inertia phase in clutch-to-clutch shifts. IFAC-PapersOnLine 48(15), 277-284 (2015)

111. Hu, Y.F., Tian, L., Gao, B.Z., et al.: Nonlinear gearshifts control of dual-clutch transmissions during inertia phase. ISA Trans. 53(4), 1320-1331 (2014)

112. Liu, Q.F., Chen, H., Gao, B.Z., et al.: Shift control of dual clutch transmission using triple-step nonlinear method. IFAC Proc. Vol. 47(3), 5884-5889 (2014)
113. Zhao, Z.G., He, L., Zheng, Z.X., et al.: Self-adaptive optimal control of dry dual clutch transmission (DCT) during starting process. Mech. Syst. Signal Process. 68-69, 504-522 (2016)

114. Kim, D., Hahn, J., Shin, B., et al.: Adaptive compensation control of vehicle automatic transmissions for smooth shift transients based on intelligent supervisor. KSME Int. J. 15(11), 1472-1481 (2001)

115. Shi, G., Dong, P., Sun, H.Q., et al.: Adaptive control of the shifting process in automatic transmissions. Int. J. Autom. Technol. 18(1), 179-194 (2017)

116. Dan, W., Shimada, T.: Improvement of CVT acceleration feeling utilizing stepwise shift control. In: Proceedings of the 5th International CTI Symposium, Shanghai, China (2016)

117. Heller, S.: The new BMW hybrid powertrain with eight-speed hybrid transmission. In: Proceedings of the 4th International CTI Symposium, Shanghai, China (2015)

118. Xu, X.Y.: Development of transmission technology for energysaving vehicles and new energy resource vehicle. J. Autom. Saf. Energy 8(4), 323-332 (2017)

119. Meisel, J.: An analytic foundation for the Toyota Prius THS-II powertrain with a comparison to a strong parallel hybrid-electric powertrain. SAE Technical Paper 2006-01-0666 (2006)

120. Suzuki, Y., Nishimine, A., Baba, S., et al.: Development of new plug-in hybrid transaxle for compact-class vehicles. SAE Technical Paper 2017-01-1151 (2017)

121. Cesiel, D., Zhu, C.: Next generation "Voltec" charging system. SAE Technical Paper 2016-01-1229 (2016)

122. Shen, D.F., Wang, C., Yu, H.S., et al.: A study on energy management strategy for compound power-split hybrid electric vehicle. Autom. Eng. 39(1), 15-22 (2017)

123. Inoue, M., Takamatsu, H., Ogami, M., et al.: New-structure motor for full hybrid electric vehicle. SAE Techical Paper 2016-01-1225 (2016)

124. Leng, H.X., Ge, H.L., Sun, J., et al.: SAIC Roewe 550 plug-in hybrid electric system. Sci. Technol. Rev. 34(6), 90-97 (2016)

125. Huang, Y., Wang, H., Khajepour, A.: Model predictive control power management strategies for HEVs: a review. J. Power Sources 341, 91-106 (2017)

126. Zhuang, W., Zhang, X., Li, D.: Mode shift map design and integrated energy management control of a multi-mode hybrid electric vehicle. Appl. Energy 204, 476-488 (2017)

127. Gao, Y., Ehsani, M.: Design and control methodology of plugin hybrid electric vehicles. IEEE Trans. Industr. Electron. 57(2), 633-640 (2010)

128. Somayajula, D., Meintz, A., Ferdowsi, M.: Designing efficient hybrid electric vehicles. IEEE Veh. Technol. Mag. 4(2), 65-72 (2009)

129. Xu, X.Y., Wu, X.X., Jordan, M., et al.: Coordinated engine-start control of single-motor $\mathrm{P} 2$ hybrid electric vehicles with respect to different driving situations. Energies 11(1), 207-229 (2018)

130. Yang, C., Jiao, X.H., Li, L., et al.: A robust $H_{\infty}$ control-based hierarchical mode transition control system for plug-in hybrid electric vehicle. Mech. Syst. Signal Process. 99, 326-344 (2018)

131. Chen, L., Xi, G., Sun, J.: Torque coordination control during mode transition for a series-parallel hybrid electric vehicle. IEEE Trans. Veh. Technol. 61(7), 2936-2949 (2012)

132. Zhao, Z.G., Lei, D., Chen, J., et al.: Optimal control of mode transition for four-wheel-drive hybrid electric vehicle with dry dual-clutch transmission. Mech. Syst. Signal Process. 105, 68-89 (2018)

133. Kum, D.: Control of engine-starts for optimal drivability of parallel hybrid electric vehicles. J. Dyn. Syst. Meas. Contr. 135(2), 450-472 (2013)

134. Yoshioka, T., Sugita, H.: Noise and vibration reduction technology in hybrid vehicle development. SAE Technical Paper 2001-011415 (2001) 
135. Wang, C., Zhao, Z., Zhang, T., et al.: Mode transition coordinated control for a compound power-split hybrid car. Mech. Syst. Signal Process. 87, 192-205 (2017)

136. Zeng, X., Yang, N., Wang, J., et al.: Predictive-model-based dynamic coordination control strategy for power-split hybrid electric bus. Mech. Syst. Signal Process. 60-61, 785-798 (2015)

137. Ehsani, M., Gao, Y., Emadi, A.: Modern electric, hybrid electric, and fuel cell vehicles: fundamentals, theory, and design. CRC Press, Boca Raton (2005)

138. Liu, J., Anwar, M., Chiang, P., et al.: Design of the Chevrolet Bolt EV propulsion system. SAE Int. J. Altern. Powertrains 5(1), 79-86 (2016)

139. Scharr, S., Vahlensieck, B., Ketteler, K.H., et al.: First results from driving and testing ZF's electric vehicle drive EVD1. In: Proceedings of 2013 T/M Symposium, Suzhou, China (2013)

140. Ruan, J.G., Walker, P.D., Zhang, N., et al.: An investigation of hybrid energy storage system in multi-speed electric vehicle. Energy 140(1), 291-306 (2017)

141. Sorniotti, A., Subramanyan, S., Turner, A., et al.: Selection of the optimal gearbox layout for an electric vehicle. SAE Int. J. Engines 4(1), 1267-1280 (2011)

142. Wu, X.X., Dong, P., Xu, X.Y., et al.: Energy conservation of electric vehicles by applying multi-speed transmissions. In: Proceedings of International Conference on Automotive Engineering, Mechanical and Electrical Engineering, Hong Kong, China, pp. 15-22 (2017)

143. Gao, B., Liang, Q., Xiang, Y., et al.: Gear ratio optimization and shift control of 2-speed I-AMT in electric vehicle. Mech. Syst. Signal Process. 50-51, 615-631 (2015)

144. Kim, Y., Kim, H., Lee, I., et al.: A speed control for the reduction of the shift shocks in electric vehicles with a two-speed AMT. J. Power Electron. 16(4), 1355-1366 (2016)

145. Zhou, X., Walker, P.D., Zhang, N., et al.: Numerical and experimental investigation of drag torque in a two-speed dual clutch transmission. Mech. Mach. Theory 79, 46-63 (2014)

146. Campbell, B., Pomerleau, M., Govindswamy, K., et al.: Integrated electric drive units with up to 2 speeds. In: Proceedings of 12th International CTI Symposium, Michigan, USA (2018)

147. Berg, M., Reimann, W., Voss, B.: DrivePacEV80 - highly integrative electric drive unit for electric vehicles. In: Proceedings of 3rd Aachen Colloquium China Automobile and Engine Technology, Beijing, China, pp. 1-32 (2013)

148. Chen, Z.F., Liu, Y.F., Fu, Y.X., et al.: Motor-torque-limited power-on upshift control in electric vehicles with automatic transmissions. Proc. Inst. Mech. Eng. D J. Autom. Eng. 230(1), 18-36 (2016)

149. He, X., Zhong, H., Niu, M.: Powertrain hybridization with electrical axle. In: Proceedings of the 4th CTI Symposium, Shanghai, China (2015)

150. Fang, S.N., Song, J., Song, H.J., et al.: Design and control of a novel two-speed uninterrupted mechanical transmission for electric vehicles. Mech. Syst. Signal Process. 75, 473-493 (2016)

151. Sorniotti, A., Holdstock, T., Pilone, G.L., et al.: Analysis and simulation of the gearshift methodology for a novel two-speed transmission system for electric powertrains with a central motor. Proc. Inst. Mech. Eng. D J. Autom. Eng. 226(7), 915-929 (2012)

152. Yuan, Y., Wu, G., He, X., et al.: Electric vehicle drivetrain development in China. In: Proceedings of ASME/ISCIE 2012 International Symposium on Flexible Automation, St. Louis, USA, pp. 597-603 (2012)

153. Chen, X., Gu, C., Yin, J., et al.: An overview of distributed drive electric vehicle chassis integration. In: Proceedings of Transportation Electrification Asia-Pacific, Beijing, China, pp. 1-5 (2014)
154. Reimagining new energy vehicles: Research innovations at Tongji University (in the USA) (2017). http://www.sciencemag. org/collections/reimagining-new-energy-vehicles-research-inno vations-tongji-university. Accessed 1 June 2018

155. Novellis, L.D., Sorniotti, A., Gruber, P., et al.: Comparison of feedback control techniques for torque-vectoring control of fully electric vehicles. IEEE Trans. Veh. Technol. 63(8), 3612-3623 (2014)

156. Fallah, S., Khajepour, A., Fidan, B., et al.: Vehicle optimal torque vectoring using state-derivative feedback and linear matrix inequality. IEEE Trans. Veh. Technol. 62(4), 1540-1552 (2013)

157. Jalali, M., Hashemi, E., Khajepour, A., et al.: Model predictive control of vehicle roll-over with experimental verification. Control Eng. Pract. 77(1), 95-108 (2018)

158. Shuai, Z., Zhang, H., Wang, J., et al.: Lateral motion control for four-wheel-independent-drive electric vehicles using optimal torque allocation and dynamic message priority scheduling. Control Eng. Pract. 24(1), 55-66 (2014)

159. Shuai, Z., Zhang, H., Wang, J., et al.: Combined AFS and DYC control of four-wheel-independent-drive electric vehicles over CAN network with time-varying delays. IEEE Trans. Veh. Technol. 63(2), 591-602 (2014)

160. Yin, G., Wang, R., Wang, J.: Robust control for four wheel independently-actuated electric ground vehicles by external yawmoment generation. Int. J. Automot. Technol. 16(5), 839-847 (2015)

161. Wang, R., Zhang, H., Wang, J.: Linear parameter-varying-based fault-tolerant controller design for a class of over-actuated nonlinear systems with applications to electric vehicles. IET Control Theory Appl. 8(9), 705-717 (2014)

162. Wang, R., Zhang, H., Wang, J.: Linear parameter-varying controller design for four-wheel independently actuated electric ground vehicles with active steering systems. IEEE Trans. Control Syst. Technol. 22(4), 1281-1296 (2014)

163. Chen, Y., Wang, J.: Fast and global optimal energy-efficient control allocation with applications to over-actuated electric ground vehicles. IEEE Trans. Control Syst. Technol. 20(5), 1202-1211 (2012)

164. Chen, Y., Wang, J.: Design and evaluation on electric differentials for over actuated electric ground vehicles with four independent in-wheel motors. IEEE Trans. Veh. Technol. 61(4), 1534-1542 (2012)

165. Khosravani, S., Kasaiezadeh, A., Khajepour, A., et al.: Torquevectoring-based vehicle control robust to driver uncertainties. IEEE Trans. Veh. Technol. 64(8), 3359-3367 (2015)

166. Chen, X., Yin, J., Wang, W., et al.: Approaches to diminish large unsprung mass negative effects of wheel side drive electric vehicles. J. Adv. Mech. Des. Syst. Manuf. 10(4), 1-17 (2016)

167. Wang, R., Jing, H., Yan, F., et al.: Optimization and finitefrequency $H_{\infty}$ control of active suspensions in in-wheel motor driven electric ground vehicles. J. Franklin Inst. 352(2), 468-484 (2015)

168. Sakai, S., Sado, H., Hori, Y.: New skid avoidance method for electric vehicle with independently controlled 4 in-wheel motors. In: Proceedings of IEEE International Symposium on Industrial Electronics, Bled, Slovenia, pp. 934-939 (1999)

169. Sakai, S.I., Sado, H., Hori, Y.: Motion control in an electric vehicle with four independently driven in-wheel motors. IEEE/ASME Trans. Mechatron. 4(1), 9-16 (1999)

170. Wang, R., Chen, Y., Feng, D., et al.: Development and performance characterization of an electric ground vehicle with independently actuated in-wheel motors. J. Power Sources 196(8), 3962-3971 (2011)

171. Zhang, G., Zhang, H., Wang, J., et al.: Fault-type identification and fault estimation of the active steering system of an electric 
vehicle in normal driving conditions. Proc. Inst. Mech. Eng. D J. Autom. Eng. 231(12), 1679-1692 (2017)

172. Zhang, H., Zhang, G., Wang, J.: $H_{\infty}$ observer design for LPV systems with uncertain measurements on scheduling variables: application to an electric ground vehicle. IEEE/ASME Trans. Mechatron. 21(3), 1659-1670 (2016)

173. Zhang, H., Zhang, G., Wang, J.: Sideslip angle estimation of an electric ground vehicle via finite-frequency $H_{\infty}$ approach. IEEE Trans. Transp. Electrif. 2(2), 200-209 (2016)

174. Goggia, T., Sorniotti, A., Novellis, L.D., et al.: Integral sliding mode for the torque-vectoring control of fully electric vehicles: theoretical design and experimental assessment. IEEE Trans. Veh. Technol. 64(5), 1701-1715 (2015)

175. Novellis, L.D., Sorniotti, A., Gruber, P., et al.: Direct yaw moment control actuated through electric drivetrains and friction brakes: theoretical design and experimental assessment. Mechatronics 26, $1-15$ (2015)

176. Wang, Y.F., Fujimoto, H., Hara, S.: Driving force distribution and control for EV with four in-wheel motors: a case study of acceleration on split-friction surfaces. IEEE Trans. Industr. Electron. 4(64), 3380-3388 (2017)
177. Hu, J.S., Wang, Y., Fujimoto, H., et al.: Robust yaw stability control for in-wheel motor electric vehicles. IEEE/ASME Trans. Mechatron. 22(3), 1360-1370 (2017)

178. Ni, J., Hu, J., Xiang, C.: Envelope control for four-wheel independently actuated autonomous ground vehicle through AFS/DYC integrated control. IEEE Trans. Veh. Technol. 66(11), 9712-9726 (2017)

179. Ni, J., Hu, J., Xiang, C.: Control-configured-vehicle design and implementation on X-by-wire electric vehicle. IEEE Trans. Veh. Technol. 67(5), 3755-3766 (2018)

180. Zhu, H., Yu, Z., Xiong, L., et al.: An anti-lock braking control strategy for 4WD electric vehicle based on variable structure control. SAE Technical Paper 2013-01-0717 (2013)

181. Leng, B., Xiong, L., Jin, C., et al.: Differential drive assisted steering control for an in-wheel motor electric vehicle. SAE Int. J. Passeng. Cars Electron. Electr. Syst. 8(2), 433-441 (2015) 